\title{
ANÁLISIS DE LAS ESTRATEGIAS DE INTERNACIONALIZACIÓN DE EDUCACIÓN SUPERIOR EN LAS UNIVERSIDADES COLOMBIANAS ${ }^{1}$
}

\author{
Analysis of the internationalization strategies in Colombian universities
}

\author{
Juan Carlos Acosta Bohorquez ${ }^{2}$ \\ Institución Universitaria Politécnico Grancolombiano \\ Bogotá, Colombia
}

\begin{abstract}
Resumen
La propuesta de esta Investigación es analizar cuáles son las estrategias de internacionalización de la educación superior que están aplicando las universidades en Colombia, para acceder al mercado académico global cada día más exigente y competitivo.

La internacionalización de la educación no debe concebirse como una serie de procesos aislados donde algunos estudiantes tienen la oportunidad de experiencias académicas fuera de su país; sino se debe ver como un proceso de planificación y de expansión para que toda la comunidad académica participe constantemente de las estrategias didácticas a nivel de educación superior. En el desarrollo de la presente investigación, se abordan diferentes estrategias que sirven como punto de partida en los procesos de internacionalización de las instituciones de educación superior (IES) colombianas.

Teniendo en cuenta que las relaciones internacionales son herramientas para promover alianzas de cooperación, apoyo a los proyectos de formación docente, extensión e investigación. Se analiza la internacionalización de la educación desde la perspectiva de las políticas institucionales propuestas para la transformación del currículo educativo.
\end{abstract}

Palabras clave:

Internacionalización, Educación, Educación superior, Estrategia

\footnotetext{
1 Acosta, J.C. (2020). Análisis de las estrategias de internacionalización de la educación superior de las universidades colombianas, Revista Punto de Vista, 12 (17), pp. 3-29.

2 Magíster en Negocios Internacionales de la Institución Universitaria Politécnico Grancolombiano. Contador público. Correo electrónico: jcacosta@poligran.edu.co
} 


\begin{abstract}
The proposal of this research is to analyze what are the strategies of internationalization of higher education that are being applied by universities in Colombia, to access to a more demanding and competitive global academic market.

The internationalization of education is not a set of isolated processes where some students have the opportunity of academic experiences outside their country; but it must be seen as a process of planning and expansion so that the entire academic community is in constant participation in the didactic strategies at the level of higher education.

In the development of this research, different strategies that serve as a starting point in the internationalization processes of Colombian higher education institutions (HEls) are addressed. Bearing in mind that international relations are tools to promote cooperation alliances, support for teacher training, extension and research projects. The internationalization of education is analyzed from the perspective of institutional policies proposed for the transformation of the educational curriculum.
\end{abstract}

Keywords:

Internationalization, Education, Higher education, Strategy

Recepción:

24.07.2020

Aceptación:

07.10 .2020

\title{
INTRODUCCIÓN
}

La Internacionalización de la Educación Superior en adelante INTES, se define como el proceso voluntario de integrar una dimensión internacional, intercultural y global en los propósitos, funciones y objetivos de la educación superior, buscando incrementar la calidad de la educación para toda la comunidad académica, con la intención de hacer una contribución significativa a la sociedad (De Wit, Hunter, Howard, \& Egron-Polak, 2015).

Por internacionalización, nos referimos también a un proceso integrador de funciones y estrategias institucionales de educación superior en una dimensión global, internacional, intercultural, comparada e interdisciplinaria, cuyo objetivo es el fomento de la conciencia global ante las problemáticas humanas (GacelÁvila, 2006).

El término de internacionalización de educación propuesto por Knight (1994), se acogió por parte de las IES desde los años noventa, donde se define como un proceso que busca integrar la dimensión internacional, intercultural y global. Este concepto ha revolucionado la definición de políticas y planes estratégicos de internacionalización, sin embargo, en la medida en que se han medido los impactos de una educación global, el término o concepto se ha complementado para abarcar el desarrollo integral de la academia a nivel internacional.

Por su parte, Hudzik (2011) define a la internacionalización como un compromiso, confirmado a través de la acción, de integrar las perspectivas internacionales y comparativas en la enseñanza, la investigación y los servicios de la educación superior. Dicho esto, la internacionalización se integra como un elemento estratégico en los procesos de transformación de los sistemas de educación superior con el fin de identificar el panorama regional sobre la dimensión internacional. 
Hans de Wit (2015, p.283), presenta una actualización de la definición de Knight, considerando que la internacionalización:

...es el proceso intencional de integrar una dimensión internacional, intercultural y global en los propósitos, funciones y provisión de la educación terciaria, buscando incrementar la calidad de la educación y la investigación para todos los estudiantes y el personal de las instituciones, con la finalidad de hacer una contribución significativa a la sociedad.

La importancia de estudiar la INTES va ligada con las grandes transformaciones que se insertan como factor de competitividad en las instituciones que educan, investigan y se relacionan con el entorno para el cumplimiento de todos sus objetivos académicos. La internacionalización ya no es una opción, por el contrario, se ha vuelto una exigencia y una directriz para todas las IES que aspiran a formar profesionales competentes con herramientas para atender las demandas laborales a nivel global (Salmi, 2014).

Existen diversos términos que se emplean para resaltar la importancia de la internacionalización. El más frecuente es el de globalización, por consiguiente, es relevante identificar la relación entre ambos. La globalización se define de diversas maneras. La descripción más trascendente y adecuada para resaltar la importancia de la INTES es:

- $\quad$ "La globalización es el flujo de tecnología, economía, conocimientos, personas, valores, ideas... a través de las fronteras. Afecta a cada país de manera diferente en virtud de la historia, las tradiciones, la cultura y las prioridades de cada nación.

- La internacionalización de la educación superior es una de las maneras en que un país responde a las repercusiones de la globalización, no obstante que respeta la idiosincrasia de la nación.". Por lo tanto, ambos conceptos, están vinculados, la globalización se considera como el punto de partida, y la internacionalización es la respuesta, y que tiene como principio la movilización de comunidades universitarias de un país a otro, así como la recepción de estudiantes extranjeros en sus universidades (Knight, 1997).

Según López Sergrera (2007), otro aspecto importante de la INTES se centra en el ámbito político y teórico que rodea la educación. Se plantean algunos conceptos como globalización, cooperación internacional, movilidad de educación transnacional, mundialización e internacionalización, sobre los cuales se desarrollan acciones para la proyección y fortalecimiento de la educación superior, que permiten al país generar competencias para el progreso, la competitividad, la consolidación económica y el posicionamiento a nivel regional e internacional. Warner (1992), por su parte, indica que existen diferentes incentivos que orientan las agendas de las universidades hacia la internacionalización, ligados a la competitividad internacional, los modelos de autodesarrollo y la transformación social en el marco de los sistemas democráticos actuales.

Mestenhauser (1998), habla sobre el potencial ilimitado que tiene la educación internacional para el desarrollo de ciertas capacidades y especialidades del conocimiento. La educación internacional enseña a conocer y a aprender. El aprender la historia de otros países, adaptarse a diferentes idiosincrasias y adquirir aptitudes de comunicación lleva a que los estudiantes rompan su paradigma y alcancen un horizonte más amplio, más allá de las fronteras de su sociedad.

Se conoce que la INTES, es un proceso generador de incentivos institucionales propios en diferentes sectores, en materia de educación superior las instituciones han buscado nuevas formas de crecimiento con calidad, en Colombia, la autonomía institucional universitaria, o el concepto económico de liberalización, juegan un papel fundamental como reguladores de las actividades del sistema económico (Rodríguez. O, 2009), dentro del cual se insertan los servicios educativos, teniendo en cuenta que la problemática para la implementación de la INTES se identifica por la falta de una regulación clara y concreta a nivel país. (Ramírez, 2011). 
El Plan Nacional Decenal de Educación 2016-2026 es una propuesta para que el sector educativo se convierta en el eje desarrollo económico y de la transformación social, dentro de los lineamientos estratégicos específicos del plan, se contextualiza de manera clara el objetivo referente a la INTES, en su numeral diecisiete: "Garantizar y fortalecer los mecanismos que favorezcan la internacionalización de la educación con criterios de calidad y pertinencia" (PNDE 2016-2026).

Por su parte, la Estrategia de Internacionalización del Consejo Nacional de Acreditación representa un esfuerzo por continuar consolidando el proceso de INTES que requiere adaptarse a las transformaciones de la globalización; por tanto, se prioriza el objetivo general que dice: "Promover y consolidar los procesos de internacionalización del Sistema de Aseguramiento de la Calidad de la Educación Superior de Colombia, en desarrollo de la política pública propuesta por el Ministerio de Educación Nacional” (CNA, 2013).

En los Estados Unidos la INTES es un tema de bastante relevancia, representado en que es el principal destino de estudiantes extranjeros de todo el mundo. De acuerdo con Akomolafe (2000), la educación es una de las industrias más significativas y lucrativas de los Estados Unidos, generando billones de dólares, por ende, existe una competencia a nivel institucional por ofrecer calidad a sus estudiantes, que son fuente invaluable de experiencia multicultural.

A nivel Latinoamérica, se han creado redes universitarias de cooperación, en las últimas dos décadas, han aportado al desarrollo de procesos y análisis referentes a la internacionalización de la educación superior. Entre estas experiencias es necesario destacar la conformación del CUIB (Consejo Universitario Interamericano) conformado por las organizaciones nacionales representativas de las universidades, con el objetivo de creación y consolidación de un espacio iberoamericano de Educación Superior y la constitución de un foro para el debate, información e intercambio de experiencias, que faciliten la coordinación de iniciativas conjuntas (Fernández. L, 2010).

Por su parte, los programas europeos de investigación y educación, más precisamente el programa ERASMUS (European Region Action Scheme for the Mobility of University Students), facilitan la movilidad de la comunidad académica dentro de los estados miembros del espacio económico europeo. También encontramos en Europa, otra serie de programas de investigación como las becas Marie Curie, que han sido el detonante para un enfoque más amplio y estratégico en la internacionalización de la educación superior en el viejo continente y han servido de ejemplos para instituciones, naciones y regiones en otras partes del mundo. La internacionalización de la educación superior ha sido influenciada por la globalización de las economías y sociedades, y el aumento en la importancia del conocimiento. Esto impulsada por una combinación dinámica y en constante evolución de razones políticas, económicas, socioculturales y académicas (De Wit, 2002).

Esta investigación está dividida en cuatro etapas; la primera consiste en la revisión bibliográfica relacionada con la internacionalización de la educación superior a nivel de organizaciones y estrategias nacionales e institucionales, en la segunda etapa se cita dentro del marco referencial a exponentes de la INTES y sus principales estrategias, en la tercera etapa se implementa el análisis de contenido de estrategias programáticas de INTES en las instituciones colombianas, y por último, el análisis y conclusiones sobre los resultados obtenidos pertinentes de la investigación. Se presentan algunas limitantes en cuanto a la información contenida en las políticas y programas de internacionalización de cada universidad, debido a que los resultados del análisis pueden no reflejar de forma contundente, la estrategia aplicada por cada IES en la actualidad y dependen también de sus objetivos de desarrollo curricular a nivel de internacionalización. 


\section{MARCO REFERENCIAL}

\section{Antecedentes}

La INTES es un estado de cambio y renovación institucional que busca incorporar una dimensión internacional e intercultural en la misión, visión y transversalmente en todas las estrategias de desarrollo para el fortalecimiento institucional, el mejoramiento de la calidad y la pertinencia del perfil de egresados, de los programas docentes, de los productos de investigación y de extensión (Gacel-Ávila, 2006).

La Organización para la Cooperación y Desarrollo Económico (OCDE, 1999), publicó un libro editado por Knight y De Wit, titulado Calidad e INTES, donde se establecen una serie de lineamientos para la evaluación de la internacionalización, igualmente se argumenta que la INTES es un tema importante en la agenda de la educación superior. Muchas iniciativas para desarrollar herramientas e instrumentos para medir la INTES han sido apropiadas por diferentes países en los últimos años. Todas estas iniciativas miden recursos, mas no resultados. (Téllez, Romero, 2013).

El proceso de revisión y medición de la calidad de la INTES ha mostrado resultados muy importantes que podrían resumirse en:

- Enfoque en dos aspectos: Crecimiento y calidad,

- Medición de acuerdo con los objetivos y metas fijadas por la institución,

- Enfoque tanto en estrategias organizacionales como programáticas,

- Mayor orientación hacia evaluar el proceso que a los resultados o el impacto,

- Dirección hacia donde el progreso es deseable y necesario,

- Aceptación de que no hay un perfil de medida ideal u óptimo,

- Enfoque en cómo los diferentes elementos se ajustan de forma integrada y estratégica,

- Necesidad de regularidad en el proceso durante un periodo de tiempo que permita reforzarlo (Téllez, Romero, 2013).

Para comprender la relevancia de la internacionalización de la educación superior, la UNESCO estableció en 1995 que el diseño de políticas para el desarrollo en la educación superior, debía adoptar a la internacionalización dado el carácter universal del aprendizaje y la investigación (Cerón, J. S. M, 2011).

En este marco la UNESCO planteó que:

La internacionalización se ve fortalecida por los actuales procesos de integración económica y política y por la creciente necesidad de entendimiento intercultural.

Es evidente la considerable expansión de diversos tipos de redes y otros mecanismos de enlace entre instituciones, profesores y estudiantes la cual, se ve facilitada por el progreso constante de las tecnologías de información y comunicación.

La cooperación internacional debe basarse, ante todo, en la asociación y la búsqueda colectiva de la calidad y la pertinencia.

Las condiciones adversas en que funcionan las IES, en especial en algunos países en desarrollo, deben ser corregidas en función de la solidaridad internacional.

Es importante promover programas e intercambios que permitan reducir los desequilibrios existentes y facilitar el acceso a los conocimientos y su transferencia. (Cerón, J. S. M, 2011).

Para Colombia los principios constitucionales y los desarrollos normativos dan la relevancia e importancia al contexto internacional, buscando desarrollar las políticas públicas nacionales, así como la creación de normativas especiales en torno a la educación superior, la investigación, la ciencia, la tecnología y la innovación. En los últimos años se han implementado significativos avances normativos directamente relacionados con la internacionalización de la educación superior (Jaramillo, García, \& Blom, 2002). 


\section{Marco teórico}

\section{Razones para la INTES}

La teoría para INTES propuesta por Knight (2005), argumenta que sin un objetivo claro y sin un conjunto de razones fundamentales, el proceso de internacionalización será solo una respuesta efímera al exponencial crecimiento de oportunidades y conexiones internacionales, estas razones se agrupan en dos categorías, las razones o motivaciones a nivel nacional y a nivel institucional.

Nivel nacional: Disponer de mecanismos y acciones encaminados a la actualización de contenidos curriculares favoreciendo la actualización en formación de profesores, ampliar las posibilidades de formación de los estudiantes mediante el aprendizaje de una segunda lengua, la movilidad en doble vía de la comunidad académica y aspirar a la acreditación internacional de algunas carreras para facilitar la captación de estudiantes extranjeros (Sebastián, J.,2011).

Nivel institucional: A nivel de estrategia institucional de internacionalización de educación superior pueden citarse los siguientes: a) Definición de los objetivos específicos, b) Fortalecimiento de una unidad de gestión y financiación del plan de acción, c) Alianzas interinstitucionales que contemplen una adecuada selección de los cooperantes con el criterio de complementariedad, calidad institucional y compromiso mutuo (Sebastián, J., 2011).

Por su parte, De Wit (2002), argumenta que existen cuatro razones fundamentales para la INTES que son: políticos, económico-financieros, académicos y culturales. Estas razones impulsan los procesos de internacionalización al Interior de las IES, por lo tanto, los países desarrollados influencian sobre la internacionalización educativa para extender su relevancia cultural y política, y a su vez económica y financiera.

\section{Modelos de planeación para la INTES}

Algunos exponentes como Knight (1994) resumen a la internacionalización como un proceso continuo y consiente al interior de las IES donde se adquieren compromisos ante la sociedad a través de la evaluación del proceso. Davis (1995) identifica factores externos e internos y cita el modelo organizativo que sugiere interiorizar elementos como la planeación, el financiamiento y evaluación de las actividades internacionales, desde la organización sistémica. Por su parte, Rudzki (1998) plantea un modelo para la internacionalización de la educación superior considerando la planeación estratégica como un elemento básico. Van der Wende (2002) propone un enfoque que contiene objetivos, políticas, estrategias, actividades y efectos sobre las instituciones a través de un esquema de correlación entre la política nacional y la institucional, implementando estrategias para la movilidad estudiantil y académica. Los autores más relevantes en materia de modelos de planeación de INTES son: (Rudzki, 1998), (De Wit, 2001) y (Hudzik, 2011).

\begin{tabular}{|llll|}
\hline Modelo & \multicolumn{1}{c|}{ Conceptualización } & \\
\hline Rudzki & Se recomienda que las decisiones y acciones a nivel macro & 1. & El cambio organizacional. \\
& se lleven a cabo antes de implementar un plan de & 2. & La innovación del currículo. \\
& internacionalización. Por ello, Rudzki (1998) propone un & 3. & El desarrollo de los recursos humanos. \\
& proceso de internacionalización institucional basado en la & 4. & La movilidad estudiantil. \\
& planeación estratégica y enfocado en la integración de la & & \\
& dimensión internacional en cuatro grandes etapas. & \\
\end{tabular}




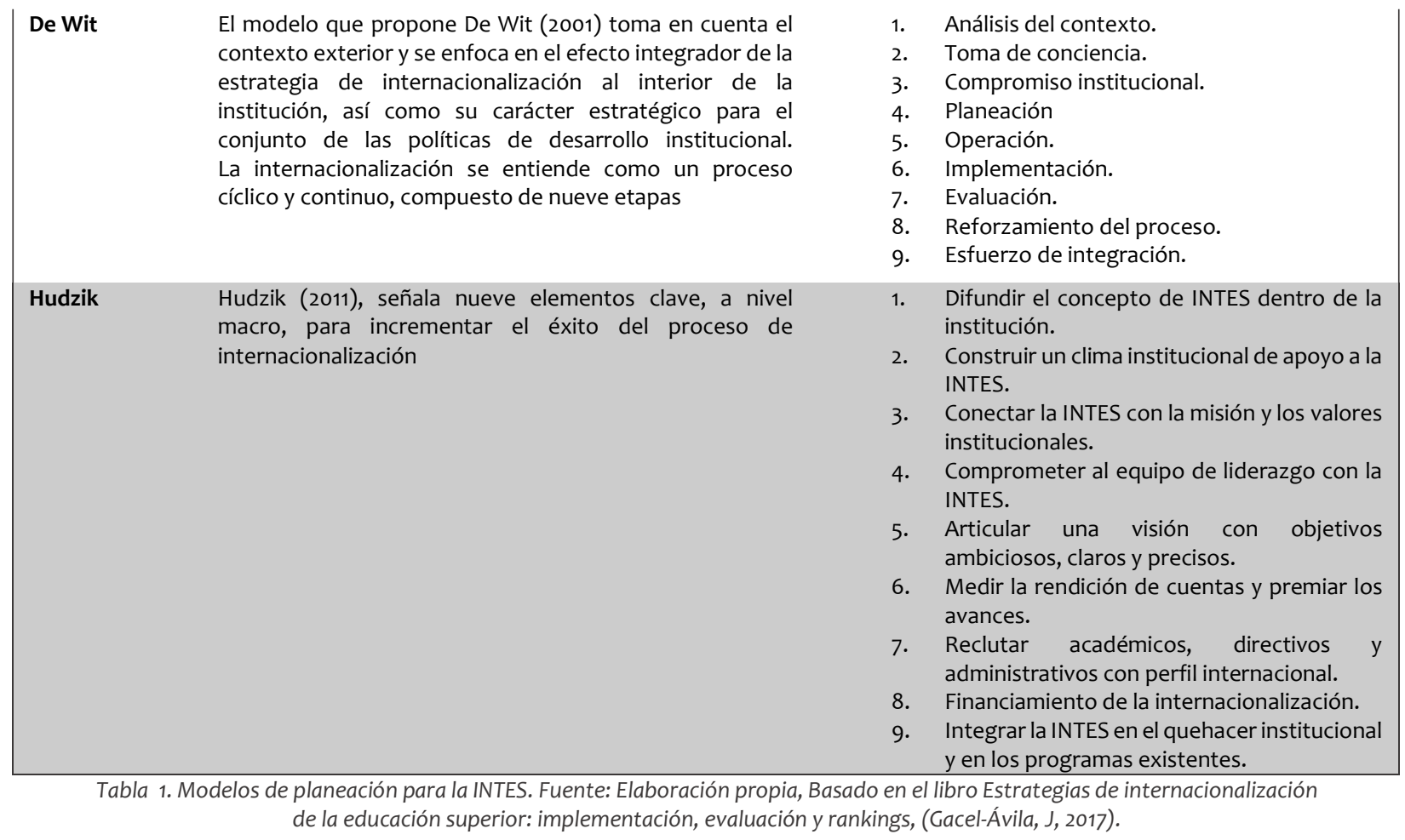

Las estrategias organizacionales o de nivel macro

Para fomentar la sostenibilidad e institucionalización del proceso de la INTES, es necesario cuidar aspectos de orden organizacional (estrategias organizacionales) y de orden académico (estrategias programáticas).

Calleja (1995), informa que la incorporación de la gestión internacional en la educación superior necesita o requiere de dos factores fundamentales: primero, la respuesta académica para lograr grupos interdisciplinarios y segundo, las políticas administrativas y burocráticas necesarias para la ejecución de cualquier iniciativa de esta naturaleza. El concepto de INTES no se puede implementar con éxito sin una sólida fundamentación hecha a partir de la clara definición de conceptos académicos como requisito para la modificación de las formas administrativas y burocráticas.

Las estrategias de nivel macro u organizacionales son las que tienen por objetivo la integración y la institucionalización de la dimensión internacional e intercultural en los siguientes grandes rubros (ver tabla 2):

- Las políticas generales de desarrollo institucional;

- La política de recursos humanos;

- Los servicios de apoyo al proceso de internacionalización

\begin{tabular}{|lll|}
\hline Estrategia & \multicolumn{2}{|c|}{ Enfoque } \\
\hline $\begin{array}{l}\text { Políticas de desarrollo } \\
\text { institucional }\end{array}$ & - & $\begin{array}{l}\text { Integración de la dimensión internacional en las diferentes políticas en materia de } \\
\text { docencia, currículo, investigación y extensión; } \\
\text { Integración de la dimensión internacional en los sistemas de planeación, presupuesto y } \\
\text { evaluación institucionales; }\end{array}$ \\
& $\begin{array}{l}\text { Establecimiento de estructuras y procedimientos administrativos buscando el perfecto } \\
\text { equilibrio entre estructuras de gestión centralizadas y descentralizadas, indispensable } \\
\text { para la correcta y eficiente promoción y administración de los programas; }\end{array}$ \\
\end{tabular}




\begin{tabular}{|c|c|c|}
\hline & & $\begin{array}{l}\text { Organización de sistemas formales e informales de comunicación y difusión para la } \\
\text { coordinación efectiva y expedita entre las diferentes áreas. }\end{array}$ \\
\hline $\begin{array}{l}\text { Desarrollo de recursos } \\
\text { humanos }\end{array}$ & $\begin{array}{l}\bullet \\
\bullet\end{array}$ & $\begin{array}{l}\text { Reconocimiento a la experiencia internacional en las políticas de reclutamiento y } \\
\text { promoción del personal académico y administrativo; } \\
\text { Oportunidades internacionales para la actualización de profesores y personal } \\
\text { administrativo; } \\
\text { Apoyos para estancias académicas y años sabáticos en el extranjero. }\end{array}$ \\
\hline Servicios de apoyo & & $\begin{array}{l}\text { Política institucional para la enseñanza de culturas e idiomas extranjeros; } \\
\text { Programa de enseñanza del español para estudiantes internacionales; } \\
\text { Asesoría cultural y académica para estudiantes locales y extranjeros; } \\
\text { Estructuras de alojamiento para profesores y estudiantes extranjeros; } \\
\text { Programas de interacción entre estudiantes locales y extranjeros; } \\
\text { Actividades extracurriculares para estudiantes extranjeros. }\end{array}$ \\
\hline
\end{tabular}

Tabla 2. Estrategias Organizacionales para la INTES. Fuente: Elaboración propia, Basado en el libro Estrategias de internacionalización de la educación superior: implementación, evaluación y rankings, (Gacel-Ávila, J, 2017).

\section{Estrategias programáticas}

Las estrategias programáticas son aquellas iniciativas que impactan directamente las actividades de naturaleza académica. Se trata del nivel operativo mediante el cual se da la implementación de los programas institucionales destinados a internacionalizar la docencia, el currículo, la investigación y la extensión. En los siguientes párrafos, se describen las estrategias más importantes en este rubro.

\begin{tabular}{|c|c|}
\hline Estrategia & Enfoque \\
\hline Internacionalización del currículo & $\begin{array}{l}\text { La OCDE define a la internacionalización del currículo como "Un currículo con una orientación } \\
\text { internacional en contenido y forma, enfocado a formar estudiantes para que se desempeñen } \\
\text { (profesional y socialmente) en un contexto internacional y multicultural" (Van der Wende, 1996). } \\
\text { A pesar del tiempo transcurrido, esta caracterización se sigue usando frecuentemente (Brewer \& } \\
\text { Leask, 2012, p. 246). La internacionalización del currículo se lleva a cabo mediante las siguientes } \\
\text { actividades: } \\
\text { - Integración de la dimensión internacional, intercultural e interdisciplinaria en los } \\
\text { - } \quad \text { programas académicos, en los programas de estudios y los métodos pedagógicos; } \\
\text { - Participación de los académicos en redes de cooperación internacional; } \\
\text { - Organización de eventos y conferencias internacionales; } \\
\text { - Enseñanza de idiomas y culturas extranjeras; } \\
\text { - Estancias de estudio o prácticas profesionales para los estudiantes en el extranjero; } \\
\text { - Utilización de la extudiantes extranjeros en la institución; } \\
\quad \text { pedagógico; }\end{array}$ \\
\hline $\begin{array}{l}\text { Internacionalización } \\
\text { investigación }\end{array}$ & $\begin{array}{l}\text { La internacionalización de la investigación se enmarca en las siguientes actividades: } \\
\begin{array}{l}\text { 1. Integración de una perspectiva internacional, intercultural, interdisciplinaria y } \\
\text { comparativa en los proyectos de investigación; } \\
\text { 2. Fomento del perfil y de la experiencia internacional de los investigadores; } \\
\text { 3. Reclutamiento de investigadores extranjeros o con reconocimiento internacional; } \\
\text { 4. Establecimiento de proyectos de investigación en colaboración con instituciones } \\
\text { extranjeras; } \\
\text { 5. Establecimiento de una política institucional en materia de fomento a las publicaciones } \\
\text { 6. Centrosionales y en colaboración internacional; }\end{array}\end{array}$ \\
\hline Internacionalización de la extensión & n respecto a esta estrategia, se puede mencionar la organización de las siguientes actividades: \\
\hline
\end{tabular}




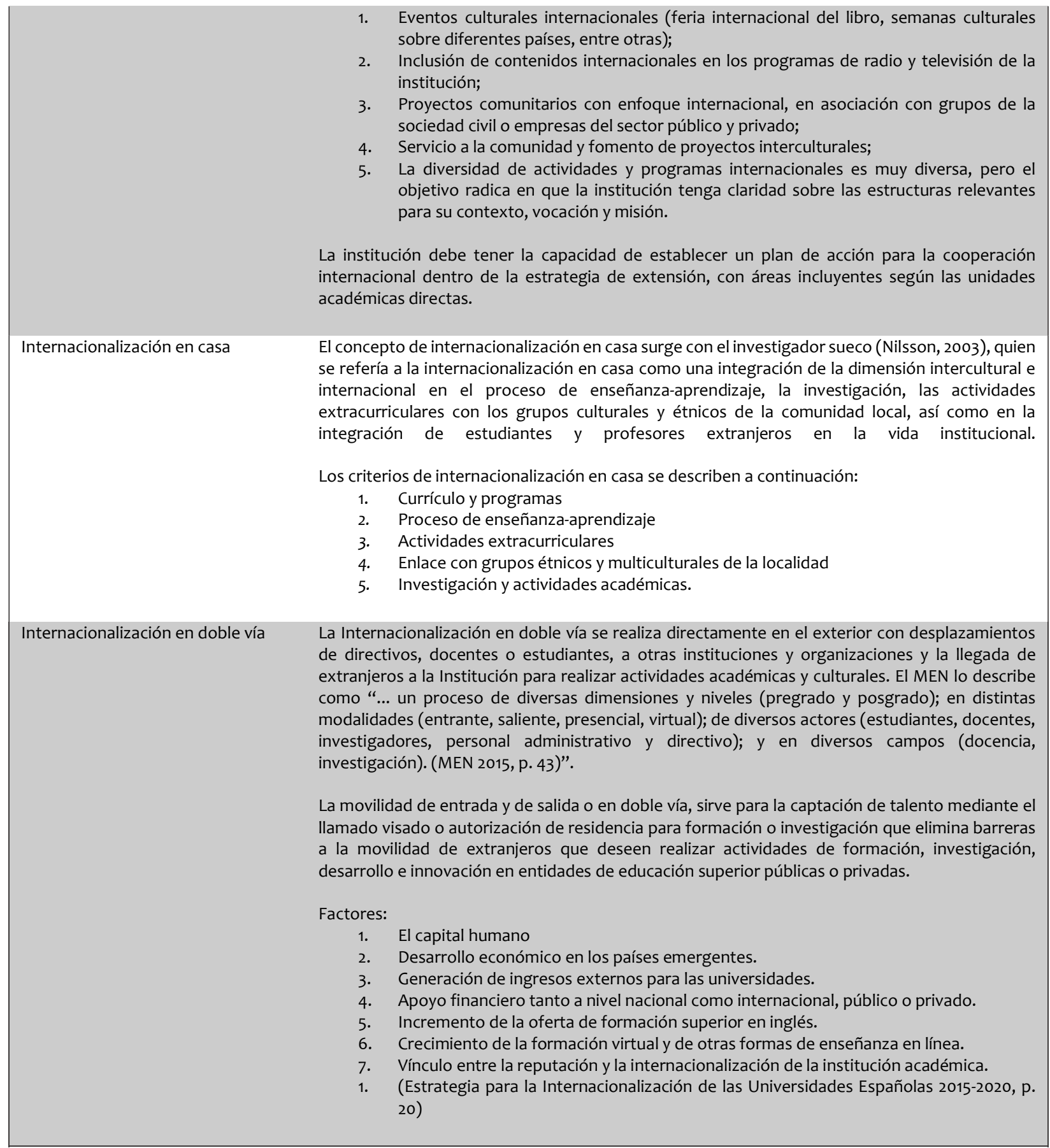

Tabla 3. Estrategias programáticas para la INTES. Fuente: Elaboración propia, Basado en el libro Estrategias de internacionalización de la educación superior: implementación, evaluación y rankings, (Gacel-Ávila, J, 2017).

Los criterios y palabras clave seleccionados para los análisis correspondientes, están contenidos en el enfoque metodológico de las estrategias programáticas que cada IES desarrolla y aplica de forma autónoma, la intención con estas palabras, es encontrar la correlación entre las políticas o planes de internacionalización de las IES colombianas y el contexto de las estrategias para INTES. Las palabras clave son extraídas de los criterios citados en las estrategias programáticas, estas palabras son seleccionadas de manera arbitraria, respetando el contexto de la estrategia. 


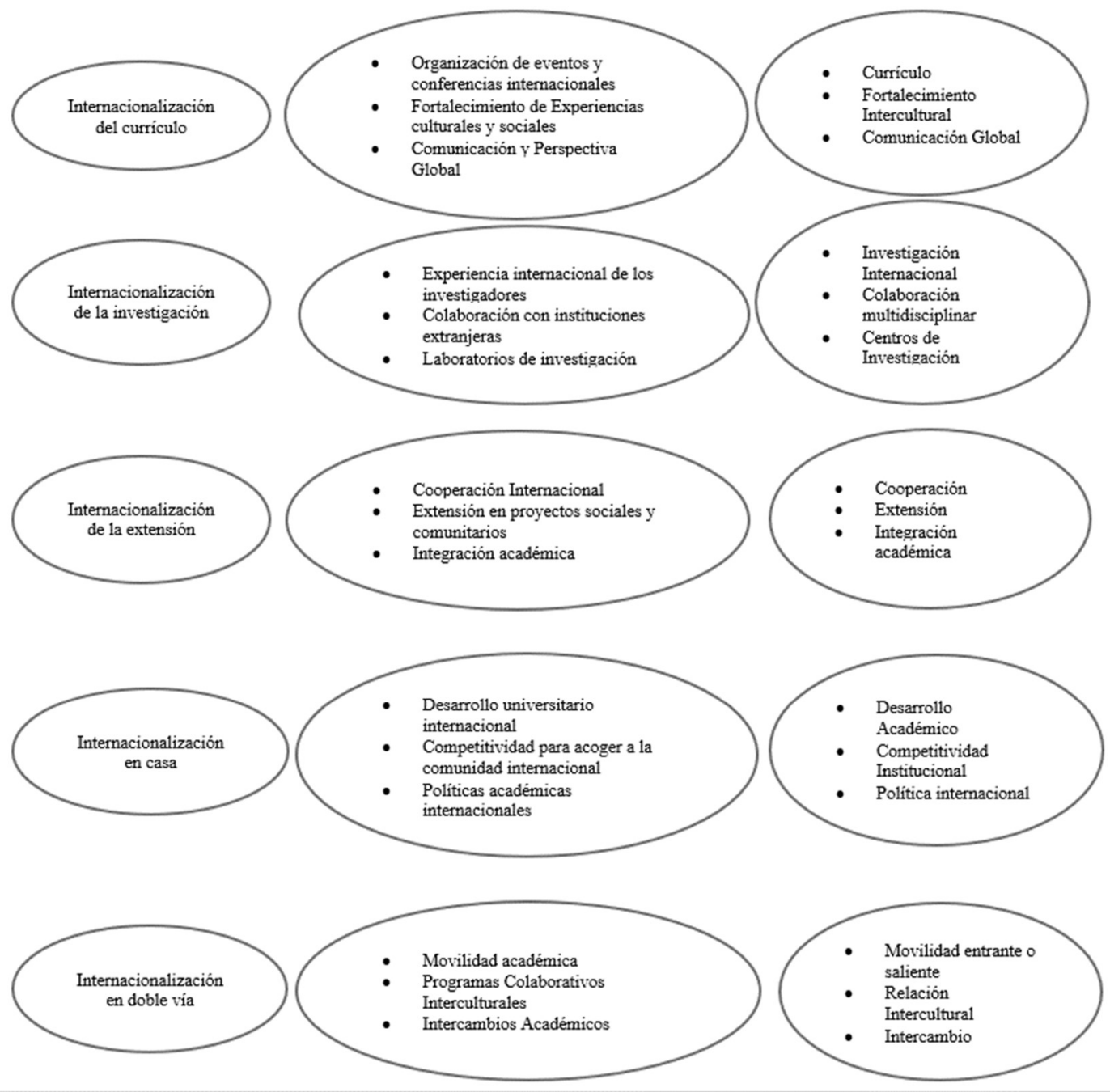

Figura 1. Criterios y palabras clave. Fuente: Elaboración propia.

Dentro de los principales hallazgos de este capítulo, encontrados que los modelos y las estrategias de INTES, son herramientas de gestión que estructuran actividades encaminadas a la obtención de las metas a nivel de internacionalización académica, por su parte se identifican razones de peso para la INTES, como lo son: Políticas, Económica-Financiera, Académicas y Culturales, que en resumidas cuentas son los pilares de desarrollo de un país.

\section{ESTRATEGIA METODOLÓGICA}

Tipo y enfoque de investigación

La investigación tiene un enfoque basado en el análisis de contenido, que resalta la investigación de tipo exploratorio, y a su vez busca tener un primer acercamiento con la temática de identificación de estrategias de 
INTES. El análisis de contenido que se propone está basado en las metodologías de Pineda Escobar (2019) y Brent Ross (2015).

El análisis se realiza con las IES que hacen parte de QS Latín América University rankings 2019. Se estudian publicaciones que se hacen desde el 2010 por parte de por la firma Quacquarelli Symonds (QS), los criterios básicos tenidos en cuenta para calificar a las universidades son:

- Impacto en la investigación y productividad,

- Compromiso docente,

- Empleabilidad,

- Impacto en línea,

- Internacionalización,

Las métricas de evaluación son:

- Reputación académica (30\%)

- Reputación del empleador (20\%)

- Proporción de profesores por alumno (10\%)

- Personal con doctorado (10\%)

- Red internacional de investigación (10\%).

- $\quad$ Citas por papel (10\%)

- Trabajos por Facultad (5\%)

- Impacto web (5\%)

La razón por la que se usa el “QS Latín América University rankings 2019” como soporte para la investigación del presente artículo, radica en que el ranking posee unos los criterios básicos y claros, que nos dan de primera mano una visión objetiva, sobre la evaluación comparativa del sistema de educación superior a nivel Latinoamérica y adicional, funciona como mecanismo de toma de decisiones para estudiantes, acerca de su expectativa de formación a nivel de académico, institucional y de reconocimiento.

\section{Método de investigación}

Esta investigación utiliza un muestreo intencional, técnica que se aplica en la investigación cualitativa para la identificación y selección de casos abundantes en información para el uso más efectivo de recursos limitados (Patton, 2002). Determinando la identificación y selección de individuos o grupos que tengan un conocimiento especial en el campo de interés (Cresswell, 2003). Adicional a la experiencia y el conocimiento, Bernard (2002) y Spradley (1979), recalcan la importancia de la disponibilidad y la disposición para comunicar experiencias y opiniones de manera estructurada, articulada y reflexiva, el propósito de aplicar el método de análisis cualitativo en esta investigación, es determinar las estrategias orientadoras de INTES en las IES colombianas, teniendo como referencia el QS Latín América University rankings 2019. Como lo indica Krippendorff (1997), la ventaja clave del método cualitativo es su flexibilidad analítica.

Los análisis determinan la frecuencia de aparición de las quince palabras clave, al igual que los quince criterios establecidos que indican el nivel de inclusión de las estrategias programáticas en las IES colombianas. Los conteos de frecuencia y análisis cualitativos se realizarán por medio de un proceso de escaneo manual de cada uno de los informes en PDF, para llevar a cabo una interpretación cualitativa del uso contextual de cada criterio y palabra clave.

El proceso se realiza con búsquedas asistidas por computador y serán resumidos en matrices de Excel para facilitar el conteo de palabras, estableciendo la correlación entre lo expuesto en las políticas, orientaciones y/o planes de internacionalización de cada universidad frente a los criterios de las estrategias programáticas para INTES establecidos en los Cuadros 5 y 6. 
Fuentes primarias

- Documentos institucionales de las IES colombianas que se analizan.

- Información sobre las INTES que se encuentran en las páginas web de cada institución para consulta pública.

- $\quad$ IES colombianas posicionadas en el QS Latín América University rankings 2019

\section{Población}

Al realizar una verificación de idoneidad y pertinencia, se escogen las quince (15) IES colombianas mejor calificadas en QS Latín América University rankings 2019, son seleccionadas a través de un muestreo intencional a conveniencia por estar dentro del rango de las universidades más importantes y reconocidas de Colombia, y que serán sometidas a un filtro excluyente para determinar aquellas universidades que posean una política de INTES claramente establecida y condensada en un documento de política disponible para consulta y descarga pública a través de su página web.

\begin{tabular}{|lll|}
\hline Puesto a nivel Latinoamérica & \multicolumn{1}{c|}{ Institución de Educación Superior } & $\begin{array}{c}\text { Política de } \\
\text { internacionalización de } \\
\text { consulta pública }\end{array}$ \\
\hline 5 & Universidad de los Andes & $\checkmark$ \\
\hline 15 & Universidad Nacional & $\checkmark$ \\
\hline 17 & Universidad de Antioquia & $\checkmark$ \\
\hline 52 & Pontificia Universidad Javeriana & $\checkmark$ \\
\hline 59 & Universidad del Rosario & $\checkmark$ \\
67 & Universidad del Valle & $\checkmark$ \\
78 & Universidad EAFIT & $\checkmark$ \\
73 & Universidad de la Sabana & \\
\hline 76 & Universidad Pontificia Bolivariana & $\checkmark$ \\
\hline 149 & Universidad Industrial de Santander UIS & $\checkmark$ \\
\hline 171 & Universidad del Norte & $\checkmark$ \\
\hline
\end{tabular}

Tabla 4. IES colombianas en el QS Latín América University rankings 2019. Fuente: Elaboración propia basada en QS Latín América University rankings 2019

Muestra

Se tomaron las quince (15) universidades colombianas mejor posicionadas en el ranking QS Latín América University, que anualmente evalúa a las cuatrocientas (400) universidades más importantes de América latina. Cinco (5) de las universidades presentes en la selección de muestra inicial, no se tendrán en cuenta por no cumplir con los siguientes criterios (ver tabla 4):

- No se tendrán en cuenta IES colombianas que tengan el contenido disperso referente a internacionalización en su página web, y que carezcan de una política o plan unificado en materia de internacionalización. 
- Tampoco entraran en el análisis de frecuencia y cualitativo aquellas universidades cuyo documento de internacionalización no sea de consulta pública a través de la web.

Con la muestra filtrada se analizarán las diez (10) IES que cumplen con las características requeridas y mencionadas:

- IES colombianas que se encuentren en la base de datos QS Latín América University.

- IES colombianas que contengan información de INTES, en documentos como la política de internacionalización de consulta disponible al público.

\section{Técnicas de recolección de información}

La recolección de la información se realizó durante los meses de enero a mayo de dos mil diecinueve (2019). Los documentos a analizar fueron descargados de Internet y de las páginas de cada IES, teniendo en cuenta que tuviesen una política de internacionalización claramente establecida y disponible para la consulta al público a través de su página web.

Para depurar, tabular y clasificar los datos se usaron búsquedas asistidas por computador que se resumieron en tablas de Excel. La metodología tiene limitaciones en cuanto a que la investigación cualitativa y el análisis de contenido utilizados, solo analizan IES con documentos de consulta pública, por ende, si alguna IES, no tiene publicado sus objetivos de internacionalización, no podría ser evaluada y no por eso se debe afirmar que la IES, no está encaminada en procesos de globalización de la educación superior.

Teniendo en cuenta que los datos analizados no están estandarizados, ni existe una política pública referente a la adopción de las INTES, la interpretación no es concluyente debido a la metodología usada y los resultados solo son aplicables a las instituciones que hicieron parte de la muestra.

\section{RESULTADOS Y DISCUSIÓN}

\section{Análisis de frecuencia}

Los hallazgos obtenidos con el análisis de frecuencia (ver tabla 5) muestran que de las diez (10) universidades analizadas, seis (6) implementan la estrategia programática de Internacionalización en doble vía, demostrando que las palabras clave "Movilidad académica", con un conteo de 124 apariciones e "intercambio", con 111 presencias, tienen unas cifras significativas y que por su alta frecuencia de citación denota que las IES colombianas la aplican con regularidad, por consiguiente se puede deducir que las universidades colombianas están apuntando fuertemente a la internacionalización de su planta académica, través de convenios de movilidad estudiantil y docente, donde el intercambio cultural es el factor primordial para el crecimiento institucional.

Por su parte la internacionalización de la investigación es acogida por la universidad de los Andes y la del Rosario, concluyendo que sus enfoques están direccionados al fomento de proyectos investigativos de índole internacional donde se requiere que sus estudiantes y docentes tengan perspectivas interculturales e interdisciplinarias a través de centros de investigación colaborativos con instituciones extranjeras.

Como se muestra en la tabla 5, la internacionalización en casa toma fuerza en IES como la universidad Industrial de Santander UIS y la Universidad del Valle, que buscan fortalecer sus programas a nivel de currículo internacional, donde las actividades extracurriculares se desarrollen en el marco de experiencias interculturales, fomentando la integración de estudiantes y profesores extranjeros en la vida institucional. 


\begin{tabular}{|c|c|c|c|c|c|c|c|c|c|c|c|c|c|}
\hline Estrategia & Palabras Clave & 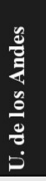 & 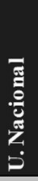 & 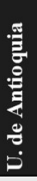 & 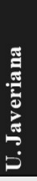 & 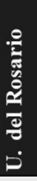 & 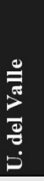 & 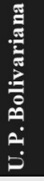 & $\frac{\Omega}{5}$ & 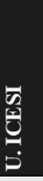 & 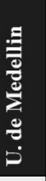 & $\begin{array}{c}\text { Frecuencia } \\
\text { palabras } \\
\text { claves }\end{array}$ & $\begin{array}{c}\text { Total } \\
\text { frecuencia } \\
\text { palabras } \\
\text { claves }\end{array}$ \\
\hline \multirow{3}{*}{$\begin{array}{l}\text { Internacionalización } \\
\text { del currículo }\end{array}$} & Cumículo & 2 & 2 & 5 & - & 8 & 4 & 9 & - & 3 & 2 & 35 & \multirow{3}{*}{94} \\
\hline & Fortalecimiento intercultural & 1 & 12 & 2 & 1 & 2 & 7 & 2 & 1 & 1 & 8 & 37 & \\
\hline & Comunicación global & 4 & 2 & 5 & - & 4 & 2 & 4 & 1 & - & - & 22 & \\
\hline \multirow{3}{*}{$\begin{array}{l}\text { Internacionalización } \\
\text { de la inves tig ación }\end{array}$} & Investigación Internacional & 25 & 4 & 21 & 5 & 18 & 17 & 12 & 2 & 2 & 2 & 108 & \multirow{3}{*}{157} \\
\hline & Colaboración multidis ciplinar & 5 & 2 & 1 & 1 & 5 & 1 & 2 & 3 & 3 & 1 & 24 & \\
\hline & Centros de Inves tig ación & 3 & 1 & 2 & 1 & 2 & 1 & 2 & 2 & 8 & 3 & 25 & \\
\hline \multirow{3}{*}{$\begin{array}{l}\text { Internacionalización } \\
\text { de la extensión }\end{array}$} & Cooperación & 12 & 10 & 8 & 2 & 4 & 10 & 5 & 4 & 7 & 10 & 72 & \multirow{3}{*}{163} \\
\hline & Extensión & - & 3 & 18 & 5 & 5 & 4 & 7 & 2 & 11 & 1 & 56 & \\
\hline & Integración académica & 2 & 1 & 3 & 6 & 8 & 1 & 10 & - & 1 & 3 & 35 & \\
\hline \multirow{3}{*}{$\begin{array}{l}\text { Internacionalización } \\
\text { en casa }\end{array}$} & Desarrollo Académico & 15 & 1 & 12 & 5 & 4 & 15 & 8 & 8 & 4 & 4 & 76 & \multirow{3}{*}{152} \\
\hline & Competitividad Institucional & 2 & 1 & 2 & 3 & 5 & 1 & 4 & 7 & - & 1 & 26 & \\
\hline & Politica internacional & 4 & 3 & 8 & 2 & 9 & 13 & 4 & 3 & 2 & 2 & 50 & \\
\hline \multirow{3}{*}{$\begin{array}{l}\text { Internacionalización } \\
\text { en doble vía }\end{array}$} & Movilidad académica & 9 & 27 & 22 & 14 & 12 & 11 & 13 & 1 & 5 & 10 & 124 & \multirow{3}{*}{276} \\
\hline & Relación Intercultural & 8 & 1 & 6 & 2 & 3 & 1 & 6 & 5 & 1 & 8 & 41 & \\
\hline & Intercambio & 14 & 6 & 13 & 9 & 8 & 11 & 11 & 6 & 17 & 16 & 111 & \\
\hline
\end{tabular}

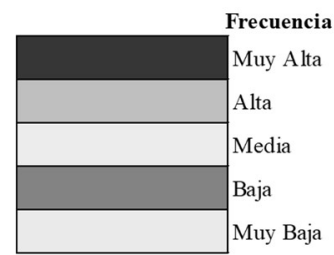

Tabla 5. Palabras determinantes en el análisis de frecuencias. Fuente: Elaboración propia basada en los documentos de políticas disponibles para consulta y descarga pública a través de su página web.

Aunque la internacionalización del currículo y de extensión presentan frecuencias considerables, aun no son calificadas a nivel de IES como las más influyentes en sus marcos de internacionalización, dando a entender que se abre una oportunidad en la socialización y entendimiento de dichas estrategias, donde se quiere catapultar su aplicación a nivel de orientación.

Respecto a las palabras analizadas, encontramos que "Movilidad académica" es la palabra con mayor frecuencia dentro de los documentos analizados, reafirmando el contexto que lo correlaciona en la estrategia de internacionalización en doble vía, y por otro lado tenemos que decir que la palabra de menor frecuencia o impacto es "Comunicación global" con solamente 22 presencias que indicaría que es un término relativamente nuevo y que deberán ser reforzado a nivel institucional por todas las IES.

A nivel de análisis nacional se observa a través de la sumatoria de frecuencias que la internacionalización en doble vía, es la razón nacional más contundente como es indicado por (Sebastián, J.,2011) quien la cita como una serie de mecanismos y acciones encaminados a la actualización de contenidos curriculares favoreciendo entre otros a la movilidad en doble vía de la comunidad académica y la aspiración de acreditación internacional de algunas carreras para facilitar la captación de estudiantes extranjeros. Por ende, están estrictamente vinculadas en el contexto de estrategia programática, y de razón nacional de internacionalización. No es conveniente dejar de lado a la internacionalización de la extensión con un sumatorio total de 163 apariciones que sugiere que, dentro del abanico de universidades, a esta se le está apuntando fuertemente con acciones de gran impacto como el proceso de cooperación, extensión e integración académica, buscando fortalecer la institucionalidad frente a los retos de educación trasfronteriza. 
La internacionalización de la investigación se establece en la parte media de la relevancia de las estrategias, dando a entender que las IES quieren potenciar sus procesos investigativos ofreciendo oportunidades de estudios y capacitación en el exterior, al igual que atrayendo capital humano extranjero con distinciones en materia de investigación. Así mismo podemos decir que la Internacionalización en casa es un caso interesante, porque sin invertir grandes recursos económicos, pueden experimentar procesos de aprendizaje interculturales y sociales, con el solo hecho de transformar sus políticas con miras a la internacionalización, por último y no menos importante, observamos que la internacionalización del currículo con 94 presencias se valora como la estrategia menos aplicada a nivel país, pero con grandes retos de cambio a nivel del fortalecimiento interno, tanto de programas académicos como de estructuras pedagógicas que se ofrecen como puentes de conocimiento internacional.

\section{Análisis cualitativo}

\begin{tabular}{|c|c|c|c|c|}
\hline \multirow[t]{2}{*}{ Estrategia } & \multirow[t]{2}{*}{ Criterios } & \multicolumn{2}{|c|}{ Implementa } & \multirow[t]{3}{*}{ Breve descripción } \\
\hline & & $\mathrm{Si}$ & No & \\
\hline \multicolumn{4}{|l|}{ U. de los Andes } & \\
\hline \multirow[t]{3}{*}{$\begin{array}{l}\text { Internacionalización } \\
\text { del currículo }\end{array}$} & $\begin{array}{l}\text { 1.Organización de eventos y conferencias } \\
\text { internacionales }\end{array}$ & & $x$ & \\
\hline & $\begin{array}{l}\text { 2.Fortalecimiento de Experiencias culturales } \\
\text { y sociales }\end{array}$ & $x$ & & $\begin{array}{l}\text { Ampliar las iniciativas extracurriculares que } \\
\text { estimulen la interculturalidad a través de alianzas } \\
\text { estratégicas con instituciones internacionales, }\end{array}$ \\
\hline & 3.Comunicacion y Perspectiva Global & & $\mathrm{x}$ & \\
\hline \multirow[t]{3}{*}{$\begin{array}{l}\text { Internacionalización } \\
\text { de la investigación }\end{array}$} & $\begin{array}{l}\text { 1. Experiencia internacional } \\
\text { investigadores }\end{array}$ & $x$ & & $\begin{array}{l}\text { Esquemas de cooperación para fomentar } \\
\text { relaciones con universidades y centros de } \\
\text { investigación internacionales. }\end{array}$ \\
\hline & 2.Colaboracion con instituciones extranjeras & $x$ & & $\begin{array}{l}\text { Construir redes de investigación y colaboración que } \\
\text { incorporen profesores, egresados y estudiantes }\end{array}$ \\
\hline & $\begin{array}{l}\text { 3.Laboratorios } \\
\text { multidisciplinaria }\end{array}$ & & $x$ & \\
\hline \multirow[t]{3}{*}{$\begin{array}{l}\text { Internacionalización } \\
\text { de la extensión }\end{array}$} & 1.Cooperación Internacional & $x$ & & $\begin{array}{l}\text { Establecer acuerdos de cooperación con un grupo } \\
\text { de países/gobiernos que la Universidad considere } \\
\text { estratégicos }\end{array}$ \\
\hline & $\begin{array}{l}\text { 2.Extensión en proyectos sociales y } \\
\text { comunitarios }\end{array}$ & & $x$ & \\
\hline & 3. Integración académica & & $x$ & \\
\hline \multirow[t]{3}{*}{$\begin{array}{l}\text { Internacionalización } \\
\text { en casa }\end{array}$} & 1.Desarrollo universitario internacional & $\mathrm{x}$ & & $\begin{array}{l}\text { Consolidar vínculos con las regiones por medio de } \\
\text { actividades de formación y desarrollo para lograr } \\
\text { un alto nivel de internacionalización. }\end{array}$ \\
\hline & $\begin{array}{l}\text { 2.Competitividad para acoger a la } \\
\text { comunidad internacional }\end{array}$ & $x$ & & $\begin{array}{l}\text { Contar con programas académicos basados en el } \\
\text { desarrollo de competencias, evaluados de forma } \\
\text { integral y sistemática con estándares } \\
\text { internacionales. }\end{array}$ \\
\hline & 3.Politicas académicas internacionales & & $x$ & \\
\hline \multirow[t]{2}{*}{$\begin{array}{l}\text { Internacionalización } \\
\text { en doble vía }\end{array}$} & 1.Movilidad académica & $x$ & & $\begin{array}{l}\text { Motivar la movilidad profesoral, la creación de } \\
\text { redes, entre otros; todos éstos recursos } \\
\text { soportados en una herramienta legal como lo son } \\
\text { los convenios de cooperación. }\end{array}$ \\
\hline & 2.Programas Colaborativos Interculturales & & $\mathrm{x}$ & \\
\hline
\end{tabular}




\begin{tabular}{|c|c|c|c|c|}
\hline & \multirow[t]{2}{*}{ 3.Intercambios Académicos } & \multirow{2}{*}{\multicolumn{2}{|c|}{$X$}} & \multirow{2}{*}{$\begin{array}{l}\text { Fortalecer las pasantías, intercambios y prácticas s } \\
\text { internacionales acorde con las políticas } \\
\text { establecidas en el documento de } \\
\text { internacionalización. }\end{array}$} \\
\hline & & & & \\
\hline \multicolumn{5}{|l|}{ U. Nacional } \\
\hline \multirow[t]{3}{*}{$\begin{array}{l}\text { Internacionalización } \\
\text { del currículo }\end{array}$} & $\begin{array}{l}\text { 1.Organización de eventos y conferencias } \\
\text { internacionales }\end{array}$ & $x$ & & $\begin{array}{l}\text { Ofrecer a la comunidad académica un abanico de } \\
\text { oportunidades académicas en el exterior. }\end{array}$ \\
\hline & $\begin{array}{l}\text { 2.Fortalecimiento de Experiencias culturales } \\
\text { y sociales }\end{array}$ & $x$ & & $\begin{array}{l}\text { Acompañamiento y asistencia a estudiantes de } \\
\text { excelencia académica para que puedan acceder a } \\
\text { las becas internacionales }\end{array}$ \\
\hline & 3.Comunicacion y Perspectiva Global & $x$ & & $\begin{array}{l}\text { Modelos internacionales de calidad de la } \\
\text { internacionalización del currículo }\end{array}$ \\
\hline \multirow[t]{3}{*}{$\begin{array}{l}\text { Internacionalización } \\
\text { de la investigación }\end{array}$} & $\begin{array}{l}\text { 1.Experiencia internacional de los } \\
\text { investigadores }\end{array}$ & $x$ & & $\begin{array}{l}\text { Consolidación del perfil del investigador en } \\
\text { plataformas mundiales de investigación }\end{array}$ \\
\hline & 2.Colaboracion con instituciones extranjeras & $\mathrm{X}$ & & $\begin{array}{l}\text { Aumento de visibilidad, impacto y posibilidades de } \\
\text { inserción en redes, consorcios y proyecto }\end{array}$ \\
\hline & $\begin{array}{l}\text { 3.Laboratorios de investigación } \\
\text { multidisciplinaria }\end{array}$ & & $X$ & \\
\hline \multirow[t]{3}{*}{$\begin{array}{l}\text { Internacionalización } \\
\text { de la extensión }\end{array}$} & 1.Cooperación Internacional & $x$ & & $\begin{array}{l}\text { Actividades de cooperación académica, movilidad y } \\
\text { relaciones internacionales con indicadores de } \\
\text { medición. }\end{array}$ \\
\hline & $\begin{array}{l}\text { 2.Extensión en proyectos sociales y } \\
\text { comunitarios }\end{array}$ & & $X$ & \\
\hline & 3. Integración académica & & $X$ & \\
\hline \multirow{3}{*}{$\begin{array}{l}\text { Internacionalización } \\
\text { en casa }\end{array}$} & 1.Desarrollo universitario internacional & & $X$ & \\
\hline & $\begin{array}{l}\text { 2.Competitividad para acoger a la } \\
\text { comunidad internacional }\end{array}$ & $x$ & & $\begin{array}{l}\text { Como estrategia en general se trata de una acción } \\
\text { dirigida y planeada, y se aplica tanto a actividades } \\
\text { de naturaleza académica como administrativa. }\end{array}$ \\
\hline & 3.Politicas académicas internacionales & $x$ & & $\begin{array}{l}\text { Creación de un sistema de información integrado } \\
\text { para la internacionalización }\end{array}$ \\
\hline \multirow[t]{3}{*}{$\begin{array}{l}\text { Internacionalización } \\
\text { en doble vía }\end{array}$} & 1.Movilidad académica & $x$ & & $\begin{array}{l}\text { Estudiantes de movilidad entrante y saliente han } \\
\text { participado en el proceso de movilidad nacional e } \\
\text { internacional }\end{array}$ \\
\hline & 2.Programas Colaborativos Interculturales & $X$ & & $\begin{array}{l}\text { Estudiantes que hablan inglés apadrinan a un } \\
\text { estudiante de movilidad internacional. }\end{array}$ \\
\hline & 3.Intercambios Académicos & & & \\
\hline \multicolumn{5}{|l|}{ U. de Antioquia } \\
\hline \multirow[t]{3}{*}{$\begin{array}{l}\text { Internacionalización } \\
\text { del currículo }\end{array}$} & $\begin{array}{l}\text { 1.Organización de eventos y conferencias } \\
\text { internacionales }\end{array}$ & & $X$ & \\
\hline & $\begin{array}{l}\text { 2.Fortalecimiento de Experiencias culturales } \\
\text { y sociales }\end{array}$ & & $X$ & \\
\hline & 3.Comunicacion y Perspectiva Global & $x$ & & $\begin{array}{l}\text { Apoyar la revisión de los currículos permitiendo un } \\
\text { mejoramiento continuo con referentes } \\
\text { internacionales. }\end{array}$ \\
\hline \multirow[t]{3}{*}{$\begin{array}{l}\text { Internacionalización } \\
\text { de la investigación }\end{array}$} & $\begin{array}{l}\text { 1.Experiencia internacional de los } \\
\text { investigadores }\end{array}$ & $X$ & & $\begin{array}{l}\text { El Intercambio de experiencias en gestión } \\
\text { universitarias, en las áreas administrativas, de } \\
\text { investigación, relacionamiento y docencia. }\end{array}$ \\
\hline & 2.Colaboracion con instituciones extranjeras & $x$ & & $\begin{array}{l}\text { Promover la visibilidad internacional por medio de } \\
\text { La promoción de actividades de investigación } \\
\text { colaborativa. }\end{array}$ \\
\hline & $\begin{array}{l}\text { 3.Laboratorios de investigación } \\
\text { multidisciplinaria }\end{array}$ & & $X$ & \\
\hline \multirow{2}{*}{$\begin{array}{l}\text { Internacionalización } \\
\text { de la extensión }\end{array}$} & 1.Cooperación Internacional & & $x$ & \\
\hline & $\begin{array}{l}\text { 2.Extensión en proyectos sociales y } \\
\text { comunitarios }\end{array}$ & $x$ & & $\begin{array}{l}\text { Diseño, estudio y aprobación de un proyecto de } \\
\text { extensión }\end{array}$ \\
\hline
\end{tabular}




\begin{tabular}{|c|c|c|c|c|}
\hline & 3. Integración académica & $x$ & & $\begin{array}{l}\text { Estimular círculos y redes de estudiantes de nivel } \\
\text { internacional }\end{array}$ \\
\hline \multirow[t]{3}{*}{$\begin{array}{l}\text { Internacionalización } \\
\text { en casa }\end{array}$} & 1.Desarrollo universitario internacional & $x$ & & $\begin{array}{l}\text { Incentivar programas académicos semi- } \\
\text { presenciales y/o virtuales entre Universidades }\end{array}$ \\
\hline & $\begin{array}{l}\text { 2. Competitividad para acoger a la } \\
\text { comunidad internacional }\end{array}$ & & $x$ & \\
\hline & 3.Politicas académicas internacionales & & $\mathrm{x}$ & \\
\hline \multirow[t]{3}{*}{$\begin{array}{l}\text { Internacionalización } \\
\text { en doble vía }\end{array}$} & 1.Movilidad académica & $\mathrm{x}$ & & $\begin{array}{l}\text { Coordinación de acuerdos internacionales y } \\
\text { normas de movilización }\end{array}$ \\
\hline & 2.Programas Colaborativos Interculturales & $x$ & & $\begin{array}{l}\text { Programas académicos normativos y aplicación de } \\
\text { la movilidad internacional. }\end{array}$ \\
\hline & 3.Intercambios Académicos & $x$ & & $\begin{array}{l}\text { Estimular el intercambio de docentes mediante la } \\
\text { formación de su personal académico en el exterior }\end{array}$ \\
\hline \multicolumn{5}{|l|}{ U. Javeriana } \\
\hline \multirow[t]{3}{*}{$\begin{array}{l}\text { Internacionalización } \\
\text { del currículo }\end{array}$} & $\begin{array}{l}\text { 1.Organización de eventos y conferencias } \\
\text { internacionales }\end{array}$ & & $x$ & \\
\hline & $\begin{array}{l}\text { 2.Fortalecimiento de Experiencias culturales } \\
\text { y sociales }\end{array}$ & $x$ & & $\begin{array}{l}\text { Preparar a sus estudiantes y futuros profesionales } \\
\text { para trabajar en un mundo interdependiente, } \\
\text { multicultural y global }\end{array}$ \\
\hline & 3.Comunicacion y Perspectiva Global & & $x$ & \\
\hline \multirow[t]{3}{*}{$\begin{array}{l}\text { Internacionalización } \\
\text { de la investigación }\end{array}$} & $\begin{array}{l}\text { 1. Experiencia internacional de los } \\
\text { investigadores }\end{array}$ & $\mathrm{x}$ & & $\begin{array}{l}\text { Promover la inserción de la actividad investigativa } \\
\text { de la Universidad en las comunidades científicas } \\
\text { internacionales. }\end{array}$ \\
\hline & 2.Colaboracion con instituciones extranjeras & $\mathrm{x}$ & & $\begin{array}{l}\text { Creando sinergias con reconocidas instituciones } \\
\text { del exterior, a través de la cooperación } \\
\text { interinstitucional }\end{array}$ \\
\hline & $\begin{array}{l}\text { 3.Laboratorios de } \quad \text { investigación } \\
\text { multidisciplinaria }\end{array}$ & $x$ & & $\begin{array}{l}\text { Promover la inserción de la actividad investigativa } \\
\text { de la Universidad en las comunidades científicas } \\
\text { internacionales. }\end{array}$ \\
\hline \multirow{3}{*}{$\begin{array}{l}\text { Internacionalización } \\
\text { de la extensión }\end{array}$} & 1.Cooperación Internacional & & $x$ & \\
\hline & $\begin{array}{l}\text { 2.Extensión en proyectos sociales y } \\
\text { comunitarios }\end{array}$ & & $x$ & \\
\hline & 3. Integración académica & $x$ & & $\begin{array}{l}\text { Construcción de una comunidad académica } \\
\text { globalizada. }\end{array}$ \\
\hline \multirow{3}{*}{$\begin{array}{l}\text { Internacionalización } \\
\text { en casa }\end{array}$} & 1.Desarrollo universitario internacional & & $x$ & \\
\hline & $\begin{array}{l}\text { 2. Competitividad para acoger a la } \\
\text { comunidad internacional }\end{array}$ & & $x$ & \\
\hline & 3.Politicas académicas internacionales & & $x$ & \\
\hline \multirow[t]{3}{*}{$\begin{array}{l}\text { Internacionalización } \\
\text { en doble vía }\end{array}$} & 1.Movilidad académica & $x$ & & $\begin{array}{l}\text { Preparar a sus estudiantes y futuros profesionales } \\
\text { para trabajar en un mundo interdependiente, } \\
\text { multicultural y global, por medio de alianzas de } \\
\text { movilidad internacional. }\end{array}$ \\
\hline & 2.Programas Colaborativos Interculturales & $\mathrm{x}$ & & $\begin{array}{l}\text { Participar en programas de movilidad estudiantil, } \\
\text { teniendo en cuenta los desempeños académicos y } \\
\text { disciplinarios. }\end{array}$ \\
\hline & 3.Intercambios Académicos & & $x$ & \\
\hline \multicolumn{5}{|l|}{ U. del Rosario } \\
\hline \multirow[t]{3}{*}{$\begin{array}{l}\text { Internacionalización } \\
\text { del currículo }\end{array}$} & $\begin{array}{l}\text { 1.Organización de eventos y conferencias } \\
\text { internacionales }\end{array}$ & $x$ & & $\begin{array}{l}\text { Ampliar vínculos regionales e internacionales que } \\
\text { establezcan redes de cooperación e integración y } \\
\text { que posicionen a la Institución }\end{array}$ \\
\hline & $\begin{array}{l}\text { 2.Fortalecimiento de Experiencias culturales } \\
\text { y sociales }\end{array}$ & & $x$ & \\
\hline & 3.Comunicacion y Perspectiva Global & $x$ & & $\begin{array}{l}\text { Escenario interdisciplinario e internacional para } \\
\text { compartir conocimientos }\end{array}$ \\
\hline
\end{tabular}




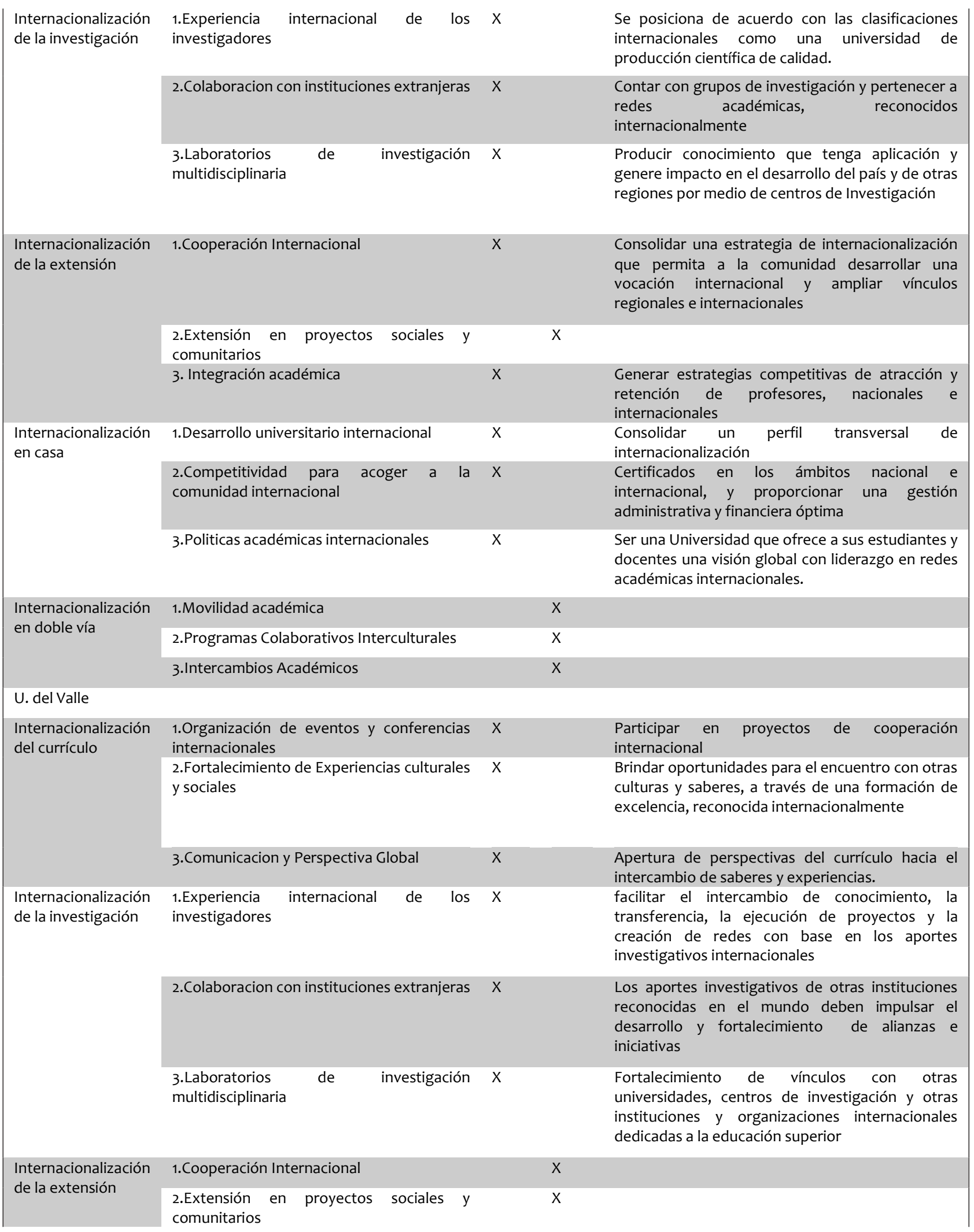




\begin{tabular}{|c|c|c|c|c|}
\hline & 3. Integración académica & & $X$ & \\
\hline \multirow[t]{3}{*}{$\begin{array}{l}\text { Internacionalización } \\
\text { en casa }\end{array}$} & 1.Desarrollo universitario internacional & $X$ & & $\begin{array}{l}\text { Compromiso en la construcción de una universidad } \\
\text { con visón internacional }\end{array}$ \\
\hline & $\begin{array}{l}\text { 2.Competitividad para acoger a la } \\
\text { comunidad internacional }\end{array}$ & $x$ & & $\begin{array}{l}\text { Dimensión internacional en las actividades } \\
\text { misionales y de apoyo institucionales como parte } \\
\text { de los procesos de desarrollo institucional }\end{array}$ \\
\hline & 3.Politicas académicas internacionales & $\mathrm{X}$ & & $\begin{array}{l}\text { Responsabilidad Institucional para crear y } \\
\text { fortalecer mecanismos de interacción con el } \\
\text { contexto educativo mundial }\end{array}$ \\
\hline \multirow[t]{3}{*}{$\begin{array}{l}\text { Internacionalización } \\
\text { en doble vía }\end{array}$} & 1.Movilidad académica & $\mathrm{X}$ & & $\begin{array}{l}\text { Fomentar los procesos de intercambio, en doble } \\
\text { vía, a través de estrategias como la movilidad } \\
\text { internacional }\end{array}$ \\
\hline & 2.Programas Colaborativos Interculturales & $X$ & & $\begin{array}{l}\text { fortalecer las relaciones internacionales con } \\
\text { instituciones de alto nivel }\end{array}$ \\
\hline & 3.Intercambios Académicos & $x$ & & $\begin{array}{l}\text { Creación artística y de proyección social mediante } \\
\text { experiencias y aprendizajes obtenidos a través del } \\
\text { intercambio internacional. }\end{array}$ \\
\hline \multicolumn{5}{|l|}{ U. P. Bolivariana } \\
\hline \multirow[t]{3}{*}{$\begin{array}{l}\text { Internacionalización } \\
\text { del currículo }\end{array}$} & $\begin{array}{l}\text { 1.Organización de eventos y conferencias } \\
\text { internacionales }\end{array}$ & $x$ & & $\begin{array}{l}\text { La gestión del currículo fundamentada en los } \\
\text { principios de integración internacional adoptando } \\
\text { pilares de interdisciplinariedad. }\end{array}$ \\
\hline & $\begin{array}{l}\text { 2.Fortalecimiento de Experiencias culturales } \\
\text { y sociales }\end{array}$ & & $\mathrm{X}$ & \\
\hline & 3.Comunicacion y Perspectiva Global & & $\mathrm{X}$ & \\
\hline \multirow[t]{3}{*}{$\begin{array}{l}\text { Internacionalización } \\
\text { de la investigación }\end{array}$} & $\begin{array}{l}\text { 1. Experiencia internacional de los } \\
\text { investigadores }\end{array}$ & & $X$ & \\
\hline & 2.Colaboracion con instituciones extranjeras & $x$ & & $\begin{array}{l}\text { Capacidad investigativa internacional en contextos } \\
\text { culturales, sociales y políticos, de idiomas y } \\
\text { culturas, con alianzas extranjeras. }\end{array}$ \\
\hline & $\begin{array}{l}\text { 3.Laboratorios de investigación } \\
\text { multidisciplinaria }\end{array}$ & & $X$ & \\
\hline \multirow{3}{*}{$\begin{array}{l}\text { Internacionalización } \\
\text { de la extensión }\end{array}$} & 1.Cooperación Internacional & & $X$ & \\
\hline & $\begin{array}{l}\text { 2.Extensión en proyectos sociales y } \\
\text { comunitarios }\end{array}$ & & $X$ & \\
\hline & 3. Integración académica & & $X$ & \\
\hline \multirow[t]{3}{*}{$\begin{array}{l}\text { Internacionalización } \\
\text { en casa }\end{array}$} & 1.Desarrollo universitario internacional & $x$ & & $\begin{array}{l}\text { Procesos de enseñanza y aprendizaje mediados } \\
\text { tecnológicamente, para contribuir a la } \\
\text { diversificación de los ambientes educativos, la } \\
\text { internacionalización y el mejoramiento de la calidad }\end{array}$ \\
\hline & $\begin{array}{l}\text { 2.Competitividad para acoger a la } \\
\text { comunidad internacional }\end{array}$ & & $X$ & \\
\hline & 3.Politicas académicas internacionales & $x$ & & $\begin{array}{l}\text { Promoción, proyección e inserción a nivel regional } \\
\text { e internacional por medio de estrategias } \\
\text { programáticas. }\end{array}$ \\
\hline \multirow[t]{3}{*}{$\begin{array}{l}\text { Internacionalización } \\
\text { en doble vía }\end{array}$} & 1.Movilidad académica & $\mathrm{X}$ & & $\begin{array}{l}\text { Fortalecimiento de proyectos, convenios y redes de } \\
\text { cooperación técnica, científica e investigativa a } \\
\text { través de la movilidad de doble vía. }\end{array}$ \\
\hline & 2.Programas Colaborativos Interculturales & & $X$ & \\
\hline & 3.Intercambios Académicos & & $\mathrm{X}$ & \\
\hline
\end{tabular}




\begin{tabular}{|c|c|c|c|c|}
\hline \multirow[t]{3}{*}{$\begin{array}{l}\text { Internacionalización } \\
\text { del currículo }\end{array}$} & $\begin{array}{l}\text { 1.Organización de eventos y conferencias } \\
\text { internacionales }\end{array}$ & $x$ & & $\begin{array}{l}\text { Ofrecer a la sociedad opciones de desarrollo } \\
\text { basadas en el saber mediante la realización de } \\
\text { eventos académicos, culturales y de transferencia } \\
\text { tecnológica en el contexto de las relaciones } \\
\text { exteriores. }\end{array}$ \\
\hline & $\begin{array}{l}\text { 2.Fortalecimiento de Experiencias culturales } \\
\text { y sociales }\end{array}$ & & $x$ & \\
\hline & 3.Comunicacion y Perspectiva Global & & $X$ & \\
\hline \multirow[t]{3}{*}{$\begin{array}{l}\text { Internacionalización } \\
\text { de la investigación }\end{array}$} & $\begin{array}{l}\text { 1. Experiencia internacional de los } \\
\text { investigadores }\end{array}$ & & $X$ & \\
\hline & 2.Colaboracion con instituciones extranjeras & & $X$ & \\
\hline & $\begin{array}{l}\text { 3.Laboratorios de investigación } \\
\text { multidisciplinaria }\end{array}$ & & $X$ & \\
\hline \multirow[t]{3}{*}{$\begin{array}{l}\text { Internacionalización } \\
\text { de la extensión }\end{array}$} & 1.Cooperación Internacional & $\mathrm{X}$ & & $\begin{array}{l}\text { Gestionar convenios para canalizar recursos de } \\
\text { cooperación provenientes de fuentes de } \\
\text { financiación nacional e internacional, como } \\
\text { mecanismo de apoyo al logro de los objetivos } \\
\text { misionales. }\end{array}$ \\
\hline & $\begin{array}{l}\text { 2.Extensión en proyectos sociales y } \\
\text { comunitarios }\end{array}$ & & $X$ & \\
\hline & 3. Integración académica & & $x$ & \\
\hline \multirow[t]{3}{*}{$\begin{array}{l}\text { Internacionalización } \\
\text { en casa }\end{array}$} & 1.Desarrollo universitario internacional & $x$ & & $\begin{array}{l}\text { Acompañar procesos de desarrollo de otras } \\
\text { instituciones en el marco de nuestra misión } \\
\text { institucional. }\end{array}$ \\
\hline & $\begin{array}{l}\text { 2.Competitividad para acoger a la } \\
\text { comunidad internacional }\end{array}$ & $x$ & & $\begin{array}{l}\text { Promover la capacidad de relación intercultural, el } \\
\text { uso de otros idiomas y la formación para vivir y } \\
\text { trabajar en un contexto internacional, que brinde } \\
\text { competitividad institucional. }\end{array}$ \\
\hline & 3.Politicas académicas internacionales & $\mathrm{X}$ & & $\begin{array}{l}\text { Asesorar a la comunidad universitaria en los } \\
\text { asuntos legales, académicos y administrativos } \\
\text { relacionados con la participación en programas de } \\
\text { relaciones exteriores. }\end{array}$ \\
\hline \multirow{3}{*}{$\begin{array}{l}\text { Internacionalización } \\
\text { en doble vía }\end{array}$} & 1.Movilidad académica & & $X$ & \\
\hline & 2.Programas Colaborativos Interculturales & $\mathrm{X}$ & & $\begin{array}{l}\text { Ofrecer a la comunidad UIS opciones de desarrollo } \\
\text { personal, en cumplimiento de la misión } \\
\text { institucional, a través de programas de intercambio } \\
\text { cultural, pasantías y programas de formación } \\
\text { avanzada. }\end{array}$ \\
\hline & 3.Intercambios Académicos & $\mathrm{X}$ & & $\begin{array}{l}\text { Fortalecer la Universidad Industrial de Santander } \\
\text { mediante programas de intercambio con } \\
\text { universidades pares }\end{array}$ \\
\hline \multicolumn{5}{|l|}{ U. ICESI } \\
\hline \multirow[t]{3}{*}{$\begin{array}{l}\text { Internacionalización } \\
\text { del currículo }\end{array}$} & $\begin{array}{l}\text { 1.Organización de eventos y conferencias } \\
\text { internacionales }\end{array}$ & $x$ & & $\begin{array}{l}\text { La Universidad promueve la realización de } \\
\text { programas académicos, con la participación de } \\
\text { investigadores, profesores y empresarios de } \\
\text { prestigio internacional }\end{array}$ \\
\hline & $\begin{array}{l}\text { 2.Fortalecimiento de Experiencias culturales } \\
\text { y sociales }\end{array}$ & & $X$ & \\
\hline & 3.Comunicacion y Perspectiva Global & & $X$ & \\
\hline \multirow[t]{3}{*}{$\begin{array}{l}\text { Internacionalización } \\
\text { de la investigación }\end{array}$} & $\begin{array}{l}\text { 1. Experiencia internacional de los } \\
\text { investigadores }\end{array}$ & & $X$ & \\
\hline & 2.Colaboracion con instituciones extranjeras & & $X$ & \\
\hline & $\begin{array}{l}\text { 3.Laboratorios de investigación } \\
\text { multidisciplinaria }\end{array}$ & & $X$ & \\
\hline
\end{tabular}




\begin{tabular}{|c|c|c|c|c|}
\hline \multirow[t]{3}{*}{$\begin{array}{l}\text { Internacionalización } \\
\text { de la extensión }\end{array}$} & 1.Cooperación Internacional & \multicolumn{2}{|l|}{$\mathrm{x}$} & \multirow{2}{*}{$\begin{array}{l}\text { Los estudiantes pueden cursar su semestre de } \\
\text { práctica en el exterior, mediante los convenios de } \\
\text { cooperación establecidos entre la universidad y los } \\
\text { ministerios de Relaciones Exteriores y de Comercio } \\
\text { Existen convenios en el exterior, mediante los } \\
\text { cuales los estudiantes a través de proyectos } \\
\text { sociales de emprendimiento pueden cursar } \\
\text { estudios de posgrado y recibir becas y auxilios } \\
\text { educativos. }\end{array}$} \\
\hline & $\begin{array}{l}\text { 2.Extensión en proyectos sociales y } \\
\text { comunitarios }\end{array}$ & $\mathrm{x}$ & & \\
\hline & 3. Integración académica & & $x$ & \\
\hline \multirow[t]{3}{*}{$\begin{array}{l}\text { Internacionalización } \\
\text { en casa }\end{array}$} & 1.Desarrollo universitario internacional & $\mathrm{x}$ & & $\begin{array}{l}\text { Desarrollo de la Semana Internacional, un espacio } \\
\text { planeado, organizado y coordinado por } \\
\text { asociaciones estudiantiles, concepto importante } \\
\text { de la internacionalización en casa. }\end{array}$ \\
\hline & $\begin{array}{l}\text { 2.Competitividad para acoger a la } \\
\text { comunidad internacional }\end{array}$ & & $\mathrm{x}$ & \\
\hline & 3.Politicas académicas internacionales & & $\mathrm{x}$ & \\
\hline \multirow{3}{*}{$\begin{array}{l}\text { Internacionalización } \\
\text { en doble vía }\end{array}$} & 1.Movilidad académica & & $x$ & \\
\hline & 2.Programas Colaborativos Interculturales & $x$ & & $\begin{array}{l}\text { Los estudiantes pueden cursar un año académico } \\
\text { con la posibilidad de obtener doble titulación a } \\
\text { través de programas de colaboración internacional. }\end{array}$ \\
\hline & 3.Intercambios Académicos & $x$ & & $\begin{array}{l}\text { Brindar apoyo a los estudiantes de intercambio } \\
\text { durante el proceso de admisión, visado y matrícula. } \\
\text { Igualmente identifica y gestiona las mejores } \\
\text { prácticas internacionales }\end{array}$ \\
\hline \multicolumn{5}{|l|}{ U. de Medellín } \\
\hline \multirow[t]{3}{*}{$\begin{array}{l}\text { Internacionalización } \\
\text { del currículo }\end{array}$} & $\begin{array}{l}\text { 1.Organización de eventos y conferencias } \\
\text { internacionales }\end{array}$ & & $x$ & \\
\hline & $\begin{array}{l}\text { 2.Fortalecimiento de Experiencias culturales } \\
\text { y sociales }\end{array}$ & $\mathrm{x}$ & & $\begin{array}{l}\text { La organización curricular tiene un carácter } \\
\text { formativo, de internacionalización cultural, } \\
\text { investigativa o de práctica profesional en los } \\
\text { programas de la Universidad. }\end{array}$ \\
\hline & 3.Comunicacion y Perspectiva Global & & $x$ & \\
\hline \multirow[t]{3}{*}{$\begin{array}{l}\text { Internacionalización } \\
\text { de la investigación }\end{array}$} & $\begin{array}{l}\text { 1. Experiencia internacional de los } \\
\text { investigadores }\end{array}$ & & $\mathrm{x}$ & \\
\hline & 2.Colaboracion con instituciones extranjeras & & $x$ & \\
\hline & $\begin{array}{l}\text { 3.Laboratorios de } \quad \text { investigación } \\
\text { multidisciplinaria }\end{array}$ & & $\mathrm{x}$ & \\
\hline \multirow[t]{3}{*}{$\begin{array}{l}\text { Internacionalización } \\
\text { de la extensión }\end{array}$} & 1.Cooperación Internacional & $x$ & & $\begin{array}{l}\text { Propiciar la interacción cultural, en otra institución } \\
\text { nacional o extranjera a través de la cooperación }\end{array}$ \\
\hline & $\begin{array}{l}\text { 2.Extensión en proyectos sociales y } \\
\text { comunitarios }\end{array}$ & & $x$ & \\
\hline & 3. Integración académica & & $x$ & \\
\hline \multirow{3}{*}{$\begin{array}{l}\text { Internacionalización } \\
\text { en casa }\end{array}$} & 1.Desarrollo universitario internacional & & $x$ & \\
\hline & $\begin{array}{l}\text { 2. Competitividad para acoger a la } \\
\text { comunidad internacional }\end{array}$ & & $x$ & \\
\hline & 3.Politicas académicas internacionales & & $x$ & \\
\hline $\begin{array}{l}\text { Internacionalización } \\
\text { en doble vía }\end{array}$ & 1.Movilidad académica & $\mathrm{x}$ & & $\begin{array}{l}\text { Se posibilita la acción interinstitucional de carácter } \\
\text { académico, investigativo, y de extensión por medio } \\
\text { de los programas de formación de la universidad }\end{array}$ \\
\hline
\end{tabular}


La División de Relaciones Internacionales, será la responsable de centralizar y canalizar el desarrollo de los convenios y acciones que posibiliten la realización de los intercambios estudiantiles

3.Intercambios Académicos

$\mathrm{X}$
Las experiencias de intercambio estudiantil tendrán una duración variable de acuerdo con los convenios, convocatorias y oportunidades específicas previamente negociadas con alianzas.

Tabla 6. Matriz de identificación de estrategias por universidad según criterios. Fuente: Elaboración propia basada en los documentos de políticas disponibles para consulta y descarga pública a través de su página web.

\begin{tabular}{|c|c|c|c|}
\hline Estrategia & Criterios & $\begin{array}{c}\text { Número de } \\
\text { implementaciones }\end{array}$ & $\begin{array}{c}\text { Total de } \\
\text { implementacione } \\
\text { s por estrategia }\end{array}$ \\
\hline \multirow{3}{*}{$\begin{array}{l}\text { Internacionalización } \\
\text { del currículo }\end{array}$} & 1.Organización de eventos y conferencias internacionales & 6 & \multirow[t]{3}{*}{15} \\
\hline & 2.Fortalecimiento de Experiencias culturales y sociales & 5 & \\
\hline & 3.Comunicacion y Perspectiva Global & 4 & \\
\hline \multirow{3}{*}{$\begin{array}{l}\text { Internacionalización } \\
\text { de la investigación }\end{array}$} & 1. Experiencia internacional de los investigadores & 6 & \multirow[t]{3}{*}{16} \\
\hline & 2.Colaboracion con instituciones extranjeras & 7 & \\
\hline & 3.Laboratorios de investigación multidisciplinaria & 3 & \\
\hline \multirow{3}{*}{$\begin{array}{l}\text { Internacionalización } \\
\text { de la extensión }\end{array}$} & 1.Cooperación Internacional & 6 & \multirow[t]{3}{*}{12} \\
\hline & 2.Extensión en proyectos sociales y comunitarios & 2 & \\
\hline & 3. Integración académica & 4 & \\
\hline \multirow{3}{*}{$\begin{array}{l}\text { Internacionalización } \\
\text { en casa }\end{array}$} & 1.Desarrollo universitario internacional & 8 & \multirow[t]{3}{*}{17} \\
\hline & $\begin{array}{l}\text { 2.Competitividad para acoger a la comunidad } \\
\text { internacional }\end{array}$ & 7 & \\
\hline & 3.Politicas académicas internacionales & 2 & \\
\hline \multirow{8}{*}{$\begin{array}{l}\text { Internacionalización } \\
\text { en doble vía }\end{array}$} & 1.Movilidad académica & 7 & \multirow[t]{3}{*}{20} \\
\hline & 2.Programas Colaborativos Interculturales & 7 & \\
\hline & 3.Intercambios académicos & 6 & \\
\hline & Muy Alta & & \\
\hline & Alta & & \\
\hline & Media & & \\
\hline & Baja & & \\
\hline & Muy Baja & & \\
\hline
\end{tabular}

Tabla 7. Implementaciones en las IES por cada criterio definido. Fuente: Elaboración propia basada en los documentos de políticas disponibles para consulta y descarga pública a través de su página web

Con el análisis cualitativo basado en los criterios establecidos para cada estrategia programática podemos dar una mirada sintética desde la óptica de las universidades hacia el enfoque sistémico de las estrategias y su aplicación.

Cada criterio tiene un nivel de implementación dentro de cada IES y esto a su vez da un peso específico a cada estrategia programática de internacionalización, empezaremos a concluir desde la estrategia con mayor implementación hasta la de menor implementación según los resultados obtenidos. 
Ratificando los datos del análisis de frecuencia, se demuestra también que en el análisis cualitativo, la internacionalización en doble vía es la estrategia más aplicada e identificada dentro de las IES colombianas, dicho esto, es normal deducir que la movilidad se constituye en motor y propulsor de importantes acciones por parte de las IES para avanzar hacia la cooperación con sus pares en el exterior, además de apoyar otras iniciativas como el fortalecimiento de la planta docente, la promoción y la diversificación de oportunidades para la formación de alto nivel de estudiantes y docentes, y la promoción de ambientes multiculturales, entre otros.

Siguiendo nuestro análisis cualitativo, tomamos la internacionalización en casa y observamos que esta estrategia está ligada fuertemente en las IES colombianas a la construcción de proyectos académicos internos que a través de experiencias se constituyen en la mejor manera de promover futuras actividades de carácter internacional, debido a que resultan no solo motivantes sino inspiradoras, teniendo como objetivo principal el desarrollo de competencias.

La internacionalización de la investigación se posiciona en un nivel medio de implementación dentro de las universidades estudiadas en esta investigación, igualmente se podría decir que es la estrategia programática que busca promover proyectos interinstitucionales, presencia de revistas en sistemas de indexación, visibilizar los resultados de investigadores y gestionar alianzas. Por esta razón las IES están uniendo esfuerzos que faciliten el relacionamiento para la colaboración investigativa a través de la gestión de redes de trabajo y el apoyo a iniciativas que permitan la formación y capacitación de investigadores.

Se evidencia que la Internacionalización del currículo se encuentra en un nivel bajo, pero no por esto quiere decir que no sea aplicada ni de intereses común dentro de las IES, un análisis preliminar de esta estrategia permite inferir que a nivel Colombia se está rompiendo el paradigma de la educación endógena, en la actualidad el trabajo enfocado en el desarrollo de competencias al interior de la comunidad académica, brinda una visión multicultural, interdependiente y competitiva, lo cual implica la apertura de los procesos curriculares hacia contextos internacionales.

Cerrando las estrategias analizadas, se encuentra a la internacionalización de la extensión con un nivel de implementación muy bajo, que la establece como la de menor relevancia dentro de las políticas de las IES colombianas, esto concluye que se debe proponer a nivel de Gobierno, un trabajo más sinérgico entre universidades y sectores público-privados para establecer actividades que promuevan proyectos con enfoque internacional, proyectos de asistencia y desarrollo internacional, programas de entrenamiento en el extranjero y eventos culturales internacionales. Todas estas son actividades extracurriculares que se realizan para internacionalizar el currículo promoverán que esta estrategia tenga mayor significancia en las IES nacionales.

En cuanto al análisis cualitativo se muestra una correlación con el análisis de frecuencias, donde a través del contexto de las políticas de internacionalización de cada IES, se evidencian las tendencias estratégicas, aunque cabe resaltar que algunas universidades establecen más de una estrategia programática en su proyecto de internacionalización, no quiere decir que todas tengan el mismo peso o relevancia, las IES pueden estar acogiendo los diferentes enfoques, que a nivel general es una de las características fundamentales para la correcta implementación de una política de internacionalización en las IES, otra característica influyente es la flexibilidad y la adaptación de varias estrategias programáticas en una misma política que le brinda a las universidad un abanico de opciones a nivel de gestión académica con objetivos internacionales.

\section{CONCLUSIONES Y RECOMENDACIONES}

Colombia carece de investigaciones que reflejen el nivel de adopción de las estrategias de internacionalización que son establecidas en las IES del país, y cuyos aportes contribuyen al fortalecimiento de las IES, así mismo, estas investigaciones serán fuente sólida para el desarrollo estructural de las políticas de internacionalización y sus

REVISTA PUNTO DE VISTA VOL. 12 No. 17 (2020) 
aplicaciones a nivel de academia. El desarrollo de esta investigación aporta un diagnóstico, mediante el análisis de las políticas de internacionalización de las diez universidades con niveles socioeconómicos y culturales diversos, que permitió obtener información valiosa y poco conocida, donde la fuente primaria son las informaciones y documentos de consulta pública a través de la web.

El comportamiento a nivel de estrategia programática obedece a una dinámica natural de cada universidad, y a través de los resultados obtenidos observamos experiencias de muy buen nivel, y con aspectos importantes a resaltar como iniciativas para abordar más de una estrategia programática, haciendo participe a la comunidad universitaria, con la idea de conformar redes y alianzas estratégicas.

Desde la perspectiva de las tendencias generales en INTES de la IES en Colombia, podemos concluir que la Internacionalización de doble vía marca la iniciativa más influyente para acceder a los sistemas académicos globales mediante procesos de movilidad e intercambio, a través de buenas prácticas como el incremento de las experiencias internacionales para estudiantes, docentes e investigadores, pero este análisis nos obliga a también entender las estrategias menos concurrentes a nivel educativo, y estas son por parte del análisis de frecuencia, la internacionalización del currículo y por parte del análisis cualitativo esta la internacionalización de la extensión que como propuesta de fortalecimiento deben tener una revisión de sus enfoques, porque puede que sus lineamientos no sean de fácil adaptación al entorno de la educación superior colombiana, en definitiva, se propone un análisis de las estrategias en mención, para determinar sus debilidades y robustecerlas en el ámbito dinámico de las IES en el país.

Los análisis realizados indican que las frecuencias medias de las estrategias programáticas tienden a la internacionalización de la investigación, para un posible encumbramiento, se propone que a nivel de IES se implementen acciones como la divulgación internacional de los productos y socialicen los resultados de investigación, estimulados desde la participación en eventos internacionales, que brindarían visibilidad y relevancia a nivel académico.

Otro hallazgo que vale la pena resaltar, son las motivaciones ligadas a las estrategias de las IES nacionales, de índole económico, social y cultural. Es evidente entonces que todas las acciones y criterios analizados en esta investigación, indican importantes avances de inserción en el panorama internacional y permiten ir creando planes institucionales más agresivos, que potencialicen las capacidades acumuladas de la comunidad académica, para enfrentar la internacionalización de una manera más sólida y eficiente.

Se recomienda profundizar sobre la construcción de estándares para elaboración de políticas de internacionalización comparables y con lineamientos propuestos por el Ministerio de Educación Nacional. Una futura línea de investigación más robusta podrá ser analizada sobre los resultados del MIDE.

También se concluye que el modelo de planeación para la INTES más adoptado por las IES, es el propuesto por Rudzki (1998), la justificación está dada por que en esta modelo se propone un proceso de internacionalización institucional basado en la planeación estratégica y enfocado en la integración de la dimensión internacional en cuatro grandes rubros: Cambio organizacional, innovación del currículo, desarrollo de recursos humanos y por último, la movilidad estudiantil, teniendo presente que en la estrategia de Internacionalización en doble vía es la más influyente a nivel de aplicación, por las IES colombianas, y que tiene contenida a la movilidad académica, como criterio de relevancia.

Para futuras investigaciones referentes a la INTES en Colombia, se recomienda entrevistar a las personas o áreas encargadas de estructurar y administrar las políticas de internacionalización de cada una de las IES analizadas, con el fin de determinar de manera directa que tipo de estrategia o metodología que implementaron, y que barreras o limitantes presentaron durante la construcción de su política general de internacionalización. 
Para desarrollos futuros de investigación en materia de INTES se sugiere a los interesados, establecer el análisis de la regulación o estandarización de las estrategias determinadas por los gobiernos locales, para la aplicación en las IES latinoamericanas, con la idea de establecer material de consulta y toma de decisiones con respecto a las tendencias en estrategias programáticas a nivel de región.

\section{REFERENCIAS BIBLIOGRÁFICAS}

Akomolafe, C.O (2000). Utilization of previous and current Research outcomes as a management tool for Educational Development. Nigeria Journal of Educational Research and Evaluation (2) 1.

Acosta de Valencia, Z. M. (2004). Proceso de internacionalización de los servicios de educación en Colombia. Archivos de Economía. Dirección de Estudios Económicos, Departamento Nacional de Planeación, República de Colombia, (266), 1 - 62.

Berelson, B. (1967): «Content Analysis», en Lindzey: Handbook of social psychology. Tomo I. New York, Lindzey.

Bernard HR. (2002). Research methods in anthropology: Qualitative and quantitative approaches. 3rd Alta Mira Press; Walnut Creek, CA: 2002.

Cerón, J. S. M. (2011). La internacionalización de la educación superior, factor clave para fortalecer la calidad educativa y mejorar las condiciones de vida de la sociedad. Revista Interamericana de Investigación, Educación y Pedagogía, RIIEP, 4(2).

Consejo Nacional de Acreditación, (CNA) 2013, Disponible en: https://www.cna.gov.co/1741/articles186362_informe_actividades.pdf. Fecha de consulta: abril de 2019.

Creswell J. (2003). Research design. Qualitative, quantitative and mixed methods approaches. Thousand Oaks: Sage; 2003.

Davis, John (1995). "University Strategies for Internationalisation in Different Intuitional and Cultural Settings". Policy and Policy Implementation in Internationalisation of Higher Education. Amsterdam: European Association for International Education. En R Bok.

De Wit, H. (2002). Internationalization of higher education in the United States of America and Europe. Westport, Greenwood Press.

De Wit, H., Hunter, F., Howard, L., \& Egron-Polak, E. (2015). Internationalization of higher education. Study. European Parliament Committee on Culture and Education. Bruselas: European Union.

Duriau, V.J., Reger, R.K. and Pfarrer, M.D. (2007), "A content analysis of the content analysis literature inorganization studies: research themes, data sources, and methodological refinements", Organizational Research Methods, Vol. 10 No. 1, pp. 5-34.

Fernández Lamarra, N. (2010). La convergencia de la educación superior en América Latina y su articulación con los espacios europeo e iberoamericano: posibilidades y límites. Revista da Avaliação da Educação Superior, Vol. $15 \mathrm{~N}^{\circ}$. 2, pp. 9-43. Disponible en: http://www.redalyc.org/articulo.oa?id=219115782002 Fecha de consulta: abril de 2019.

Gacel-Ávila, J. (1999). Internacionalización de la educación superior en América Latina y el Caribe: reflexiones y lineamientos. Guadalajara: Organización Universitaria Interamericana.

Gacel-Ávila, J. (2017). Estrategias de internacionalización de la educación superior: implementation, evaluation y rankings. México: UNESCO-IESALC.

Guerrero, Ornar (2000). Administración pública. México, Léxico de Política/UNAM/ UAM/FLACSO. 
Hudzik, J. (2011). Comprehensive internationalization: from concept to action. Washington: nafsa. Recuperado de: https://www.nafsa.org/_/File/_/comprehensive_izn_spanish.pdf.

Jaramillo, I. C. (2002). La Dimensión Internacional de la Universidad Colombiana: Análisis de la situación actual y perspectivas. Bogotá D.C.

Jaramillo, I. C. (2003a). La internacionalización de la educación superior y su dinámica en Colombia. LCSHD Paper Series. No.82. World Bank.

Jaramillo, I. C. (2003b). La internacionalización de la Universidad Colombiana. Un instrumento para el cambio. Bogotá D.C.: Asociación Colombiana de Universidades - ASCUN.

Jaramillo, I. C., García, P., \& Blom, A. (2002). Colombian Higher Education in the Global Market. The World Bank.

Krippendorf, K. (1997): Metodología de análisis de contenido. Teoría y práctica. Barcelona, Paidós.

Knight, J. (1994). Internationalization: Elements and Checkpoints. Ottawa: Canadian Bureau for International Education.

Knight, J. (1997). "Internationalization of Higher Education: A Conceptual Framework", in Knight, J. and De Wit, H. (Eds). Internationalization of Higher Education in Asia Pacific Countries, European Association for International Education Publications, Amsterdam.

Knight, J. (2005). Un modelo de internacionalización: respuesta a nuevas realidades y retos. Educación superior en América Latina. La dimensión internacional. Bogotá: Banco Mundial/ Mayol, 1-38.

Knight, J. (2005). Internationalization of higher education: new directions, new challenges. IAU Global Survey Report, (pp. 41-42).

López Sergrera, F. (2007). Notas para un estudio comparado de la educación superior a navels mundial. En Escenarios mundiales de la educación superior. Analysis global y estudios de casos (pp. 1 - 85). CLACSO, Consejo Latinoamericno de Ciencias Sociales.

Ministerio de Educación Nacional (MEN) y Colombia Challenge Your Knowledge CCYK® (2015a). Guías para la Internacionalización de la Educación Superior. Gestión de la Internacionalización. Disponible en: https://issuu.com/hans268/docs/1.gestion_de_inter. Fecha de consulta: abril de 2019.

Ministerio de Educación, Cultura y Deporte, Secretaría General de Universidades, (2016). Estrategia para la Internacionalización de las Universidades Españolas 2015-2020, p. 20.

Múnera, L. (2012, agosto 30). El camino errático y retórico de una reforma (Ni calidad, ni derecho, ni sistema, ni autonomía). Universidad Nacional de Colombia. Recuperado a partir de http://www.bdigital.unal.edu.co/7391/1/leopoldomuneraruiz1.pdf.

Paige, R. M. (2005). Internationalization of Higher Education: Performance Assessment and Indicators. Nagoya Journal of Higher Education, 5(8), 99-122.

Patton M. Qualitative research and evaluation methods. 3a. Ed. Thousand Oaks: Sage Publications; 2002.

Pineda-Escobar, Maria A. (2019) "Moving the 2030 agenda forward: SDG implementation in Colombia", Corporate Governance: The International Journal of Business in Society, Vol. 19 Issue: 1, pp.176-188, https://doi.org/10.1108/CG-11-2017-0268.

Plan Nacional Decenal de Educación (PNDE) 2016-2026. Disponible en: http://www.plandecenal.edu.co/cms/media/herramientas/PNDE\%20FINAL_ISBN\%20web.pdf. Fecha de consulta: abril de 2019.

Ramírez, A. A. (2011). Condiciones para la internacionalización de la educación superior: entre la inclusión y la exclusión en un mundo globalizado. Globalización e internacionalización de la educación superior, 8(2), 152 - 164. http://doi.org/Universitat Oberta de Catalunya. 
Rodríguez Otalora, J. A. (2009, junio). ELEMENTOS PARA LA DISCUSIÓN DE LA INTERNACIONALIZACIÓN DE LA EDUCACIÓN SUPERIOR COLOMBIANA. Revista de la Facultad de Ciencias Económicas: Investigación Y Reflexión. Universidad Militar Nueva Granada, XVII (1), 109 - 122.

Ross, R.B., Pandey, V. and Ross, K.L. (2015), "Sustainability and strategy in US agri-food firms: an assessment of current practices”, International Food and Agribusiness Management Review, Vol. 18 No. 1, pp. $17-48$.

Rudzki, R. E. (1998). The strategic management of internationalization: towards a model of theory and practice. Thesis submitted for the Degree of Doctor of Philosophy at the School of Education. University of Newcastle upon Tyne, United Kingdom.

Salmi, J., \& Otros. (2014). Reflexiones para la política de internacionalización de la educación superior en Colombia. Bogotá D.C.: Ministerio de Educación Nacional. Recuperado a partir de http://www.mineducacion.gov.co/1621/w3article-342477.html.

Sebastián, J. (2011). Dimensiones y métrica de la internacionalización de las universidades. Universidades, 61, 316.

Scott, P. (1998). Massification, Internationalization and Globalization. En the Globalization of Higher Education (pp. 109-129). Buckingham, Reino Unido: SRHE and Open University Press.

Spradley JP (1979). The ethnographic interview. Holt, Rinehart \& Winston; New York: 1979.

Téllez. F, Romero. D. (2013). Importancia y calidad de los procesos de internacionalización de las INTERNACIONALIZACION DE LA EDUCACION SUPERIOR en el Marco de la acreditación: Encuentros Regionales CNA. En linea en https://www.cna.gov.co/1741/articles186502_Encuentros_regionales_2013.pdf

UNESCO, Marco de acción prioritaria para el cambio y el desarrollo de la educación superior: http://www.educacion.unesco.org/educprog/wche/presentacion.htm

Van Der Wende, Marijk (2002). "The International Dimension in National Higher Education Polic Internacionalizacion de la Educacion Superior: ¿What Has Changed in Europe in the Last Five Years?" European Journal of Education: Research, Development and Policy, Vol. 36 Issue 4, pp. 431-441.

Warner, Gary (1992). "Internationalization Models and the Role of the University". International Education Magazine, September Fall, p. 21.

Wolf, L., \& de Maura Castro, C. (2004, agosto). ¿Educación pública o privada? una falsa disyuntiva. Revista Perspectiva. Educación: la tarea pendiente de América Latina. Recuperado a partir de http://www.revistaperspectiva.com/archivos/revista/No\%205/19_dossier_disyuntiva.pdf. 